Pontifícia Universidade $C_{\text {atólica }}$

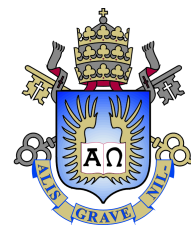

Rafael Basilio Chaves

\title{
Development of an Autonomous Collision Avoidance System Based on Fuzzy Control
}

Dissertação de Mestrado

Dissertation presented to the Programa de Pós-Graduação em Engenharia Mecânica of the Departamento de Engenharia Mecânica do Centro Técnico Científico da PUC-Rio, in partial fulfillment of the requirements for the degree of Mestre em Engenharia Mecânica

Advisor : Prof. Hans Ingo Weber

Co-Advisor:

Prof. Georg Rill 


\section{Development of an Autonomous Collision Avoidance System Based on Fuzzy Control}

Dissertation presented to the Programa de Pós-Graduação em Engenharia Mecânica of the Departamento de Engenharia Mecânica do Centro Técnico Científico da PUC-Rio, in partial fulfillment of the requirements for the degree of Mestre em Engenharia Mecânica.Approved by the undersigned commission:

Prof. Hans Ingo Weber

Advisor

Departamento de Engenharia Mecânica - PUC-Rio

Prof. Georg Rill

Co-Advisor

Mechanical Engineering Department - Ostbayerische

Technische Hochschule Regensburg

Prof. Ricardo Teixeira da Costa Neto

Departamento de Engenharia Mecânica - PUC-Rio

Prof. Mauro Speranza Neto

Departamento de Engenharia Mecânica - PUC-Rio

Dr. Guilherme Rodrigues Sampaio de Paula Departamento de Engenharia Mecânica - PUC-Rio

Prof. Márcio da Silveira Carvalho Vice Dean of Graduate Studies Centro Técnico Científico - PUC-Rio

Rio de Janeiro, December 20 th, 2017 
All rights reserved.

\section{Rafael Basilio Chaves}

Rafael holds a Bachelor of Science degree from Pontifical Catholic University of Rio de Janeiro, obtained in July 2014.

Bibliographic data

Chaves, Rafael Basilio

Development of an Autonomous Collision Avoidance System Based on Fuzzy Control / Rafael Basilio Chaves; advisor: Hans Ingo Weber; co-advisor: Georg Rill. - 2017.

v., 69 f: il. color. ; $30 \mathrm{~cm}$

Dissertação (mestrado) - Pontifícia Universidade Católica do Rio de Janeiro, Departamento de Engenharia Mecânica.

Inclui bibliografia

1. Engenharia Mecânica - Teses. 2. Dinâmica de Veículos;. 3. Controle Fuzzy;. 4. Sistemas de Evitamento de Colisão;. 5. Direção Autônoma;. 6. Controle ABS;. I. Weber, Hans Ingo. II. Rill, Georg. III. Pontifícia Universidade Católica do Rio de Janeiro. Departamento de Engenharia Mecânica. IV. Título. 


\section{Acknowledgments}

First and foremost, to my parents, who have worked hard to give me the best possible education and a comfortable life. For understanding me when I decided to leave Brazil and for supporting me to make my childhood dream come true.

To my wife Raquel, for being the main reason of my happiness, for supporting me in all my decisions and for motivating me every day to pursue my objectives.

To my advisors Prof. Dr. Ing. Georg Rill and Prof. Dr. Ing. Hans Weber, which I admire personally and professionally, for making this work possible and for giving me the opportunity to have access to a valuable knowledge acquired in many decades of work.

To Prof. Dr. Ing. Thomas Schaeffer, for hiring me as a Scientific worker and for providing all the necessary equipment I needed to develop this research.

To my friends from the Labor und Kompetenzzentrum Mehrkörpersimulation and from Audi AG, for being the best friends I could find in Germany. 


\section{Abstract}

Chaves, Rafael Basilio; Weber, Hans Ingo (Advisor); Rill, Georg (Co-Advisor). Development of an Autonomous Collision Avoidance System Based on Fuzzy Control. Rio de Janeiro, 2017. 69p. Dissertação de Mestrado Departamento de Engenharia Mecânica, Pontifícia Universidade Católica do Rio de Janeiro.

This work presents a concept for a collision avoidance system simulated using 3D-models of three different vehicles implemented in MATLAB ${ }^{\circledR}$. Two of the vehicle data sets were built with generic information, used to characterize mid-size and full-size vehicles. These standard vehicles were used in initial simulations and for demonstration of some concepts. The third data set was built with information from the Apollo N, a super sportive car. These different data sets were used to evaluate the controller's capacity to work with a range of vehicles, with different sizes and driving characteristics. The approach for triggering the system is based on the time-to-colision (TTC) estimation. This concept was adopted to recognize when the driver is not able to avoid an accident. After being triggered, the system must decide which maneuver is the most appropriate for the given friction and risk conditions. The first goal of this work is to develop an autonomous braking system which evaluates the risk of a possible collision and decides if the driver is able to avoid it. Once the driver has not enough time to react, the system must trigger the brakes automatically in order to avoid the accident. The vehicle is equipped with an embedded Anti-lock Brake System (ABS) developed using Fuzzy control. The ABS controller's performance was evaluated in simulations using the data sets and tested in a scaled vehicle. In more critical cases, when there is low friction, the vehicle is not able to brake in a reasonable distance. Considering this situation, an autonomous steering control was implemented in order to make an alternative avoidance maneuver. This second system was evaluated in simulations using vehicles with understeering and oversteering characteristics. The results pointed out that the autonomous steering control was able to perform avoidance maneuvers in a reasonable range of lateral accelerations, in vehicles with different driving tendencies.

\section{Keywords}

Vehicle Dynamics; Fuzzy Control; Collision Avoidance Systems; Autonomous Driving; ABS Control; 


\section{Resumo}

Chaves, Rafael Basilio; Weber, Hans Ingo; Rill, Georg. Desenvolvimento de um Sistema Autônomo de Evasão de Colisões Baseado em Controle Fuzzy. Rio de Janeiro, 2017. 69p. Dissertação de Mestrado - Departamento de Engenharia Mecânica, Pontifícia Universidade Católica do Rio de Janeiro.

O presente trabalho apresenta um conceito para um sistema de evasão de colisões, simulado usando modelos 3D de três veículos diferentes implementados em MATLAB ${ }^{\circledR}$. Dois destes veículos foram parametrizados com dados genéricos, caracterizando automóveis de médio e grande porte. Em seguida, utilizados para realização de simulações iniciais e demonstração de conceitos. O terceiro conjunto de dados foi construído com informações do Apollo N, um veículo super esportivo. Estes diferentes conjuntos de dados foram utilizados para avaliar a capacidade do controlador de trabalhar com veículos de diferentes portes e dinâmicas de direção. A abordagem para acionar o sistema baseia-se no cálculo do tempo para a colisão (TTC; timeto-collision). O conceito foi adotado para detectar situações onde o motorista não é capaz de evitar um acidente. Depois de ser acionado, o sistema deve decidir qual manobra é a mais apropriada, dadas as condições de aderência da pista e o risco associado. O primeiro objetivo deste trabalho é desenvolver um sistema autônomo de frenagem que deve ser capaz de avaliar o risco de uma possível colisão e decidir se o condutor é capaz de evitá-la. Uma vez que o motorista não tenha tempo suficiente para reagir, o sistema deve acionar os freios automaticamente a fim de evitar um possível acidente. Além disso, o veículo possui um sistema anti-travamento (ABS), desenvolvido usando controle Fuzzy. O desempenho do controlador ABS foi avaliado em simulações usando os conjuntos de dados e testado em um veículo em escala. Em casos mais críticos, quando há baixa aderência, o veículo não é capaz de frear em uma distância razoável. Levando-se em consideração tal situação, um controle autônomo de esterçamento também foi desenvolvido, visando a possibilidade de uma manobra alternativa de evasão. Este segundo sistema foi avaliado em simulações utilizando veículos com características subesterçantes e sobreesterçantes. Os resultados mostraram que o controle de esterçamento foi capaz de realizar manobras evasivas produzindo valores razoáveis de acelerações laterais, em veículos com diferentes dinâmicas de direção.

\section{Palavras-chave}

Dinâmica de Veículos; Controle Fuzzy; Sistemas de Evitamento de Colisão; Direção Autônoma; Controle ABS; 


\section{Kurzfassung}

Chaves, Rafael Basilio; Weber, Hans Ingo (Prüfer); Rill, Georg (Zweitprüfer). Development of an Autonomous Collision Avoidance System Based on Fuzzy Control. Rio de Janeiro, 2017. 69p. Dissertação de Mestrado Departamento de Engenharia Mecânica, Pontifícia Universidade Católica do Rio de Janeiro.

Die vorliegende Arbeit präsentiert ein Konzept für ein Kollisionsvermeidungssystem. Dieses wird anhand von drei verschiedenen 3DFahrzeugmodellen mit Hilfe von MATLAB simuliert. Zwei der FahrzeugDatensätze basieren auf generischen Informationen, die jeweils ein Automobil der Mittelklasse und der Oberklasse repräsentieren. Diese Standardfahrzeuge wurden für anfängliche Simulationen und zur Demonstration einiger Konzepte verwendet. Das dritte Fahrzeugmodell wurde mit Hilfe der Daten des Sportwagens Apollo N aufgebaut. Durch die Verwendung der verschiedenen Datensätze soll die Funktionsfähigkeit der Regelung auch bei verschiedenen Fahrzeugtypen mit unterschiedlichen Dimensionen und Fahreigenschaften überprüft werden.Die Grundlage zum Auslösen des Systems ist die Abschätzung der Zeit bis zur Kollision (TTC; time-to-collision). Dieses Konzept wurde aufgegriffen, um zu entscheiden, wann der Fahrer nicht mehr in der Lage ist einen Unfall zu vermeiden. Nachdem das System ausgelöst wird muss dieses anhand der Traktionsverhältnisse und Gefahrensituation entscheiden, welches Manöver am besten geeignet ist. Das erste Teilziel ist die Entwicklung eines autonomen Bremssystems, welches eine bevorstehende Kollision erkennen muss und entscheidet ob der Fahrer die Kollision eigenständig vermeiden kann. Sobald der Fahrer nicht mehr genug Zeit hat selbst zu reagieren, muss das System die Bremsen automatisch betätigen um den Unfall zu vermeiden. Hierzu ist das Fahrzeug mit einem Antiblockiersystem (ABS) ausgestattet. Dieses wurde mit Hilfe eines Fuzzy-Kontrollers realisiert. Die Funktionstüchtigkeit der ABS-Regelung wurde mit Simulationen und anhand eines realen, skalierten Fahrzeugmodells getestet. In kritischen Situationen, kann es aufgrund der Traktionsverhältnisse vorkommen, dass das Fahrzeug nicht mehr in der Lage ist innerhalb einer ausreichenden Strecke zum Stehen zu kommen. Um für solche Situationen ein alternatives Ausweichmanöver anwenden zu können, wurde ein automatischer Lenkeingriff implementiert. Dieses System wurde anhand von Simulationen an Fahrzeugmodellen mit Übersteuernden und Untersteuernden Eigenschaften überprüft. Die Ergebnisse zeigten, dass die automatische Lenkeingriff-Regelung in der Lage war auch bei Fahrzeugen 
mit unterschiedlichen Fahreigenschaften Ausweichmanöver unter Einhaltung angemessener Querbeschleunigungen durchzuführen.

\section{Schlüsselwörter}

Fahrzeugdynamik; Fuzzy Reglung; Kollisionsvermeidungssystem; Autonomem Fahren; ABS Reglung; 


\section{Contents}

1 Introduction $\quad 13$

$\begin{array}{lll}1.1 & \text { Notation } & 15\end{array}$

$\begin{array}{lll}1.2 & \text { Coordinate Systems } & 16\end{array}$

2 Vehicle Longitudinal Dynamics $\quad 17$

2.1 Friction and Tilting Limits 18

$\begin{array}{ll}2.2 \text { Braking in a Turn } & 19\end{array}$

3 Vehicle Lateral Dynamics $\quad 22$

$\begin{array}{ll}3.1 & \text { Steering Tendency } \\ & 24\end{array}$

4 Mathematical Model $\quad 28$

4.1 Wheels and Tires 28

4.1.1 Longitudinal Slip and Force Generation 29

4.1.2 Lateral Slip and Force Generation 30

4.1.3 Combined Lateral and Longitudinal Forces 30

$\begin{array}{lll}4.2 & \text { Suspension } & 31\end{array}$

$\begin{array}{lll}4.3 & \text { Aerodynamics } & 33\end{array}$

4.4 Drive and Brake Forces 34

5 Fuzzy Control $\quad 36$

5.1 Time to Collision 36

5.2 Braking Control 36

5.3 ABS Adaptation for the Apollo N 39

5.4 Autonomous Braking Maneuver 43

5.5 Steering Control 44

5.6 Autonomous Avoidance Maneuver 45

$\begin{array}{lll}5.7 & \text { Combined Maneuver } & 47\end{array}$

6 Implementation and Experiments $\quad \mathbf{5 0}$

6.1 Acquisition System $\quad 51$

6.2 Model Validation $\quad 52$

6.3 ABS Controller 53

6.3.1 Braking in Straight Line $\quad 53$

6.3.2 Braking and Steering $\quad 56$

6.3.3 Autonomous Braking Test $\quad 58$

$\begin{array}{ll}6.4 \text { Vision System Concept } & 59\end{array}$

6.4.1 Algorithm Development $\quad 59$

6.5 Recommendations for the Autonomous Steering Control 63

$\begin{array}{lll}7 & \text { Conclusions } & 64\end{array}$

$\begin{array}{ll}\text { References } & 66\end{array}$ 


\section{List of Figures}

1.1 Vehicle coordinate systems. Taken from (30) 16

$\begin{array}{lll}2.1 & \text { Forces acting at the vehicle. } & 17\end{array}$

2.2 Vehicle original trajectory. 20

2.3 Locking front and rear wheels in a turn. 20

3.1 Lateral forces acting at the vehicle. 22

3.2 Loads at the front inside wheel during a turn. 23

3.3 Different driving tendencies for a vehicle. 24

3.4 Steering gradients for a linear model. 25

3.5 Steering gradients for a non-linear model. 26

4.1 Tire force generation. $\quad 29$

4.2 Combined tire force generation. Taken from (30) 31

4.3 Double wishbone suspension with push rod system. 32

4.4 Measured downforces on each axle. 33

4.5 Simple dry friction model. $\quad 35$

4.6 Enhanced Braking Model. 35

5.1 Input and output fuzzy sets. 38

5.2 Vehicle Longitudinal speed compared to front and rear wheels' speeds. 38

5.3 Vehicle Longitudinal Acceleration. 38

5.4 Input fuzzy sets for the Apollo tires. 39

5.5 Longitudinal acceleration output at the Apollo $\mathrm{N}(\mu=1.2) . \quad 39$

5.6 Comparison between wheels and vehicle's speeds at the Apollo N. $\quad 40$

5.7 Simulation outputs for braking in reduced friction conditions $(\mu=$ $0.5)$.

5.8 Working ranges for an ABS controller.

5.9 Slip variation during braking maneuvers.

5.10 Autonomous braking maneuver. 43

5.11 Fuzzy control surface for the steering control system. 44

5.12 Steering inputs for oversteering and understeering vehicles. 45

5.13 Lateral acceleration and steering inputs. 46

5.14 Lateral acceleration and steering inputs for $\mu=0.3$. 47

5.15 Avoidance maneuver in a low friction surface $(\mu=0.3)$.

5.16 Avoidance maneuver performed at the Apollo N. 47

5.17 Comparison of a combined steering and braking maneuver with pure steering. $\quad 48$

5.18 Changing between braking and steering maneuvers. 49

6.1 Scaled Vehicle. 50

6.2 Simplified circuit schematic. $\quad 51$

6.3 Data Acquisition GUI. $\quad 52$

6.4 Double Lane Change maneuver comparison. 53

6.5 Scaled Vehicle braking without ABS. 54

6.6 Scaled Vehicle braking with ABS. 54 
6.7 ABS test in low friction. $\quad 55$

6.8 Braking and Steering maneuver using the scaled model. 56

6.9 Braking and Steering maneuver using the scaled model and ABS controller. $\quad 57$

6.10 Autonomous Braking Maneuver using the scaled model. 58

6.11 Image convertion from RGB to grayscale. 60

6.12 Grayscale after threshold operation. $\quad 60$

6.13 Mask introduction at the thresholded image. 61

6.14 Line estimation algorithm. 62

6.15 Final output of the vision system. 62 


\section{List of Tables}

2.1 Vehicle parameters and expected acceleration limits. 19

3.1 Vehicle parameters and overturning limits. 23

4.1 Results of Downforce measurement. 34

5.1 Fuzzy control rules for the ABS system. 37

5.2 Typical friction coefficients for different roads. 40

5.3 Fuzzy control rules for the Steering control system. 45 


\section{Introduction}

A report from the American National Highway Safety Administration (NHTSA), points that $80-90 \%$ of road traffic accidents are caused by driver distractions or errors (25). Such incidents are responsible for 1.25 million of deaths every year (37). Based on this information, the road safety organizations around the world are working to make collision avoidance systems as a feature present in the next generation of automotive vehicles. The European New Car Assessment Programme (EuroNCAP) (10) is one of the most engaged organizations in this field, being responsible for assessing the safety of the current vehicles.

The vehicle safety developments in the last decades were remarkable, some features such as the Anti-lock Braking System (ABS), Electronic Brake Force Distribution (EBD), Traction Control and other safety systems are currently available in a large number of vehicles. Recently, automated driving systems are also being developed. The Adaptive Cruise control, Lane Keeping warning and Fatigue Detection System are examples of the latest improvements in vehicle safety.

The first generation of collision avoidance systems was developed in the 90 's using sensors for measuring the distance between the vehicle and an obstacle and calculating the time-to-collision (TTC). With this information, the vehicle should be able to perform an emergency braking maneuver (8). Two decades after, the most recent researches on collision avoidance systems are being focused on the use of vision-based systems $(23,2)$. This evolution makes possible not only the detection of an obstacle, but also the acquisition of information about its size and position. The use of vision systems opens the possibilities for performing emergency steering maneuvers. This feature can also make possible to evolute the collision avoidance systems to full autonomous systems in the future, including driving, overtaking and pedestrian avoidance capabilities. These functionalities should be developed with a great support of computer companies (27) and tested in a future competition of full autonomous vehicles (33).

The network communication between vehicles is also being studied. Concepts of Vehicle-to-Vehicle (V2V) and Vehicle-to-Infrastructure (V2I) networks 
are under investigation in order to provide interaction between a vehicle and the environment. These networks act as support systems and can be used, for example, to map the position of all the cars and pedestrians nearby $(34,35,20)$.

Collision avoidance systems are the most recent research topic in the field of vehicle safety (23). The actuation of these systems vary from a simple Collision Avoidance Warning (CAW) to automated systems such as the Emergency Automatic Brake (EAB), calling the driver's attention to a possible accident or actuating the brakes automatically in order to avoid frontal collisions. Such Emergency Automatic Braking systems are already present in a small number of vehicles in the market. These systems are supposed to reduce significantly the number of accidents involving pedestrians. Some possible scenarios of these occurrences are listed in $(19,22,36)$.

The pre-crash systems are another feature of this generation of vehicles. They are supposed to detect a crash before it happens and activate the airbags, belt pretentioners or also the brakes in order to mitigate the effect of a future collision. In the biggest amount of the cars, crashes are identified by using acceleration and pressure mesurements, but some premium vehicles are already eqquiped with radars. These sensors are used not only in pre-crash systems, but also in another ones, such as the Adaptive Cruse Control (ACC). This feature will be even more common in a near future, once the new autonomous vehicles will demand a series of new sensors, which can be used to estimate the risk of a possible crash. A good example of it is the Audi A8 (Generation D5), developed to have a level 3 of autonomous driving. The car uses the brakes and the active suspension system to mitigate the effect of front and side crashes.

In this work, two Fuzzy controllers were developed in order to execute avoidance maneuvers and improve the overall safety of the vehicle. A basic knowledge of vehicle dynamics was used in preliminary analysis to make both controllers as simple as possible, once the main purpose is to show in a very simple way how these systems can be developed and implemented in the next generation of road vehicles. A similar idea of having braking and steering controls working together is proposed in (4). Both systems were evaluated in a range of different simulated scenarios $(1,3)$ and some of the concepts were tested in a scaled vehicle.

The first step is to develop a controller, which is able to perform autonomous braking maneuvers. These maneuvers must be done in a way that the vehicle stability is not prejudiced. For this reason, the controller must be able to reproduce the same behavior of a normal ABS system. The main challenge to develop this controller is the considerable range of values for the tire-road friction coefficient and the lack of a commercial sensor for measuring 
it in real-time. Estimations of this value are possible $(6,28,5,9)$, but normally they demand a huge effort. Besides that, we must consider that real roads have a non-uniform friction distribution, which makes the estimation even less precise.

In commercial systems, variables such as slip and side-slip angle are estimated in order to detect when the tires are on their limit of force generation (7). They are used as the main reference for most of the vehicle stability systems. Tire longitudinal slips can be estimated in a easiest way by comparing the wheel's angular speed and the vehicle's velocity. What does not hold for the lateral slips and side-slip angle. These variables can be estimated, for example, by implementing an electronic system with the so called bicycle model (29) embedded in the vehicle and feeding it with sensors' information in real-time.

The next step is to develop an autonomous steering control. In case that there is no possibility to stop the car before the collision, a steering control must be able to perform a lane change in order to prevent the accident. In this case, the controller may actuate by receiving a position feedback coming from a camera. This real-time video processing capability is possible thanks to the advances in the computer science field, which made the hardware equipment much more powerful and cheaper during the last decade. Currently, camera feedbacks are being used, for example, in autonomous overtaking and lane detection systems $(26,24)$.

The Fuzzy control strategy was taken as the best approach for implementing both controllers, once it is able to deal with complex systems in a simple way. The possibility to control a specific system without any need to linearize it makes the Fuzzy systems to be commonly used in vehicle controls $(23,17,11)$. Considering that tires have a highly non-linear behavior, but the force generation characteristics are well known, if a proper rule base is built, the Fuzzy controller must be able overcome these non-linearities.

\section{1}

\section{Notation}

The notation used for describing positions, velocities and accelerations is the same from (31). A position vector, is defined by the letter $r$ with subscripts for identifying the initial and final point and the reference system. The vector $r_{A B, 0}$, for example represents a displacement between the points $A$ and $B$, written at the earth-fixed coordinate system. The same procedure is valid for angular quantities, where for example, $\omega_{12,0}$ represents the angular velocity between the systems 1 and 2 written at the earth-fixed coordinate system.

Considering that the coordinate systems are defined by three orthogonal 
vectors $\left(e_{x}, e_{y}\right.$ and $\left.e_{z}\right)$, a three dimensional rotation can be defined by a sequence of rotations in each one of these axes. Defining $\alpha, \beta$ and $\gamma$ as angles in $\mathrm{X}, \mathrm{Y}$ and $\mathrm{Z}$ respectively, the matrices to express elementary rotations in each of these axes are defined by

$A_{\alpha}=\left[\begin{array}{ccc}1 & 0 & 0 \\ 0 & \cos \alpha & -\sin \alpha \\ 0 & \sin \alpha & \cos \alpha\end{array}\right], A_{\beta}=\left[\begin{array}{ccc}\cos \beta & 0 & \sin \beta \\ 0 & 1 & 0 \\ -\sin \beta & 0 & \cos \beta\end{array}\right]$ and $A_{\gamma}=\left[\begin{array}{ccc}\cos \gamma & -\sin \gamma & 0 \\ \sin \gamma & \cos \gamma & 0 \\ 0 & 0 & 1\end{array}\right]$

\section{2}

\section{Coordinate Systems}

The model is defined over many coordinate systems. The first one is the earth-fixed referential $\left(x_{0}, y_{0}, z_{0}\right)$, which has the $z$-coordinate in the opposite direction of the gravity force. The second coordinate system $\left(x_{C}, y_{C}, z_{C}\right)$ is located at the vehicle's center of mass, where $x_{0}$ points to the front of the vehicle, $y_{0}$ to the left, $z_{0}$ upwards, for corresponding the definitions in the ISO 8855 directive.

The position of a vehicle's center of mass changes according to the loads on each axle, for this reason, a third fixed coordinate system $\left(x_{F}, y_{F}, z_{F}\right)$ was defined at the vehicle's front axle in order to make all the calculations in a system which is always fixed in the same point of the chassis. Each wheel has also its own fixed coordinate system, these systems are useful to calculate the tire forces, wheel rotation axis and other important quantities. Figure 1.1 shows the vehicle and all its coordinate systems.

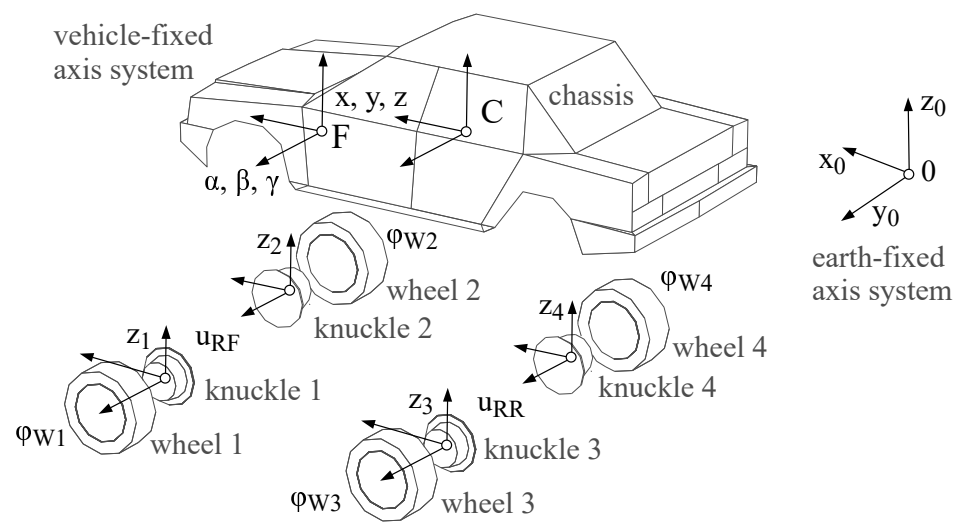

Figure 1.1: Vehicle coordinate systems. Taken from (30) 


\section{2}

\section{Vehicle Longitudinal Dynamics}

The forces acting on the vehicle during acceleration or braking motions are the main topic of study in the longitudinal dynamics. This preliminary analysis has the objective to define the best approach to establish rules for the fuzzy autonomous braking controller. The longitudinal forces are influenced by some factors as terrain inclination and aerodynamic characteristics. In this simple model, the terrain inclination will be neglected, but the aerodynamic forces must be considered, once they have a large influence at the Apollo's dynamic behavior. These aerodynamic characteristics will be presented with more details in Section 4.3.

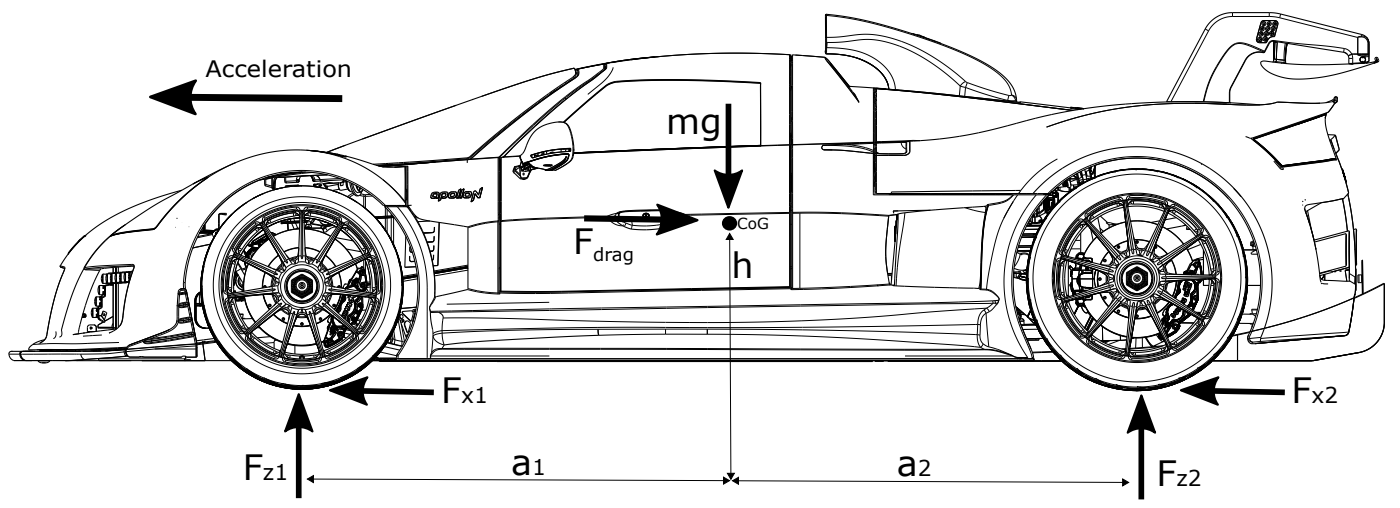

Figure 2.1: Forces acting at the vehicle.

To model the wheel loads and the vehicle acceleration, a force diagram at the $x-z$ plane was built, as shown in Figure 2.1. After analyzing it, three equations of motion can be deducted. In a generic approach, which considers a 4 -wheel drive vehicle, the longitudinal motion caused by the tire forces is described by Equation 2-1. For front wheel driving or rear wheel driving vehicles, the values of $F_{x 1}$ or $F_{x 2}$ will be set as zero. When braking, both forces will become negative and the vehicle will produce deceleration

$$
m \dot{v}=F_{x 1}+F_{x 2}-F_{d r a g}
$$

Equation 2-2 tells that the maximum tractive force $F_{x}$ is a function the wheel loads and the friction coefficient between tire and road. It is important to remember that due to the downforces, the loads $F_{z 1}$ and $F_{z 2}$ are increasing with a quadratic speed dependency. Equation 2-3 shows the force balance in 
the vertical direction. The last equation (2-4) is obtained by the torque balance at the vehicle's $y$-axis.

$$
\begin{gathered}
F_{x}=\mu F_{z}, \\
F_{z 1}+F_{z 2}-m g-F_{D 1}-F_{D 2}=0, \\
F_{z 2} a_{2}-F_{z 1} a_{1}-\left(F_{x 1}+F_{x 2}\right) h=0 .
\end{gathered}
$$

Finally, considering that the drag effect described in Equation 2-1 and the downforces $F_{D 1}$ and $F_{D 2}$ are known, the wheel loads on each axle can be modeled as follows:

$$
\begin{aligned}
& F_{z 1}=F_{D 1}+m g \frac{a_{2}}{a_{1}+a_{2}}-\frac{h}{a_{1}+a_{2}}\left(m \dot{v}-F_{d r a g}\right), \\
& F_{z 2}=F_{D 2}+m g \frac{a_{1}}{a_{1}+a_{2}}+\frac{h}{a_{1}+a_{2}}\left(m \dot{v}-F_{d r a g}\right) .
\end{aligned}
$$

The wheel load variation during a braking or acceleration motion is called dynamic load transfer and together with the friction coefficient, it is the limiting factor for the maximum longitudinal accelerations. This phenomena helps to understand, for example, that in a braking situation the front wheels will improve their capacity to generate decelerations, once they have increasing load. On other hand, a special attention should be given to the rear wheels because they are more susceptible to lock due the decreasing load while braking. A more complete description of this simple model is found in (30).

\section{1}

\section{Friction and Tilting Limits}

For most of the cases, the friction limit will determine the maximum longitudinal force. According the formulation done in the beginning of this Chapter, this force is a function of the current wheel load and the friction coefficient. Considering that the loads are varying with the acceleration, the maximum forces on each axle $\left(F_{x 1}\right.$ and $\left.F_{x 2}\right)$ can be written as:

$$
F_{x 1}=\mu F_{z 1} \quad \text { and } \quad F_{x 2}=\mu F_{z 2} .
$$

Assuming a flat surface with a constant friction coefficient, Equation 2-7 can be rewritten as

$$
m \dot{v}=\mu\left(F_{z 1}+F_{z 2}\right)-F_{d r a g} .
$$

In normal passenger cars driving in dry and paved roads, the maximum longitudinal acceleration is normally defined by $\frac{\dot{v}}{g}=1$. This value will be considered to estimate the friction limits for the standard vehicles. For the 
Apollo N, there is a valuable earning on the friction limits because of the load increasing due to downforce. In (30), the relation between these limits and the downforces is expressed as

$$
-\mu\left(\frac{F_{D 1}}{m g}+\frac{F_{D 2}}{m g}+1\right)-\frac{F_{d r a g}}{m g} \leq \frac{\dot{v}}{g} \leq \mu\left(\frac{F_{D 1}}{m g}+\frac{F_{D 2}}{m g}+1\right)-\frac{F_{d r a g}}{m g} .
$$

In some special cases, the tilting limit determines if the wheel can lift-off during braking or acceleration, this condition occurs when $F_{z 1} \leq 0$ or $F_{z 2} \leq 0$. The maximum accelerations before the lift-off are defined in (30) as

$$
-\frac{a_{1}}{h} \leq \frac{\dot{v}}{g} \leq \frac{a_{2}}{h}
$$

The friction and tilting limits are the key parameters for defining the controller's rule base. Using Equations 2-9, 2-10 and the data sets, they were calculated for each vehicle in order to understand what is the limiting factor for a braking maneuver. The parameters for each vehicle and the maximum acceleration until reaching the friction and tilting limits are shown in Table 2.1 .

Table 2.1: Vehicle parameters and expected acceleration limits.

\begin{tabular}{|l|c|c|c|c|c|}
\hline Parameters & $a 1[\mathrm{~m}]$ & $a 2[\mathrm{~m}]$ & $\mathrm{h}[\mathrm{m}]$ & Friction $[\dot{v} / \mathrm{g}]$ & Tilting $[\dot{v} / \mathrm{g}]$ \\
\hline Mid-size & 1.11 & 1.49 & 0.54 & 1 & 2.05 \\
\hline Full-size & 1.4 & 1.5 & 0.57 & 1 & 2.46 \\
\hline Apollo N (at top speed) & 1.62 & 1.1 & 0.37 & 2.3 & 4.4 \\
\hline
\end{tabular}

As expected, all the vehicles would reach the friction limit before the tilting limits. After this point, the approach for the ABS controller rule base can be simplified, once there is no need to care about a possible wheel lift. This assumption can be made for most of passenger cars, but should be reconsidered when implementing the system in SUVs with a higher center of mass position.

\section{2}

\section{Braking in a Turn}

Braking the vehicle in a turn is a critical situation. If the front wheels are locked, the vehicle loses the capacity to generate lateral forces, what will make it drive in a straight line even if the wheels are steered. In vehicles without an ABS system, there is a compromise to lock the front wheels before the rear ones, since a rear wheel locking can bring the vehicle to a dangerous and unstable situation. In order to show these behaviors, a simulation scenario was 
built considering the mid-size vehicle driving at $80 \mathrm{~km} / \mathrm{h}$ with $45^{\circ}$ of steering wheel angle. Figure 2.2 shows the natural path at the turn.

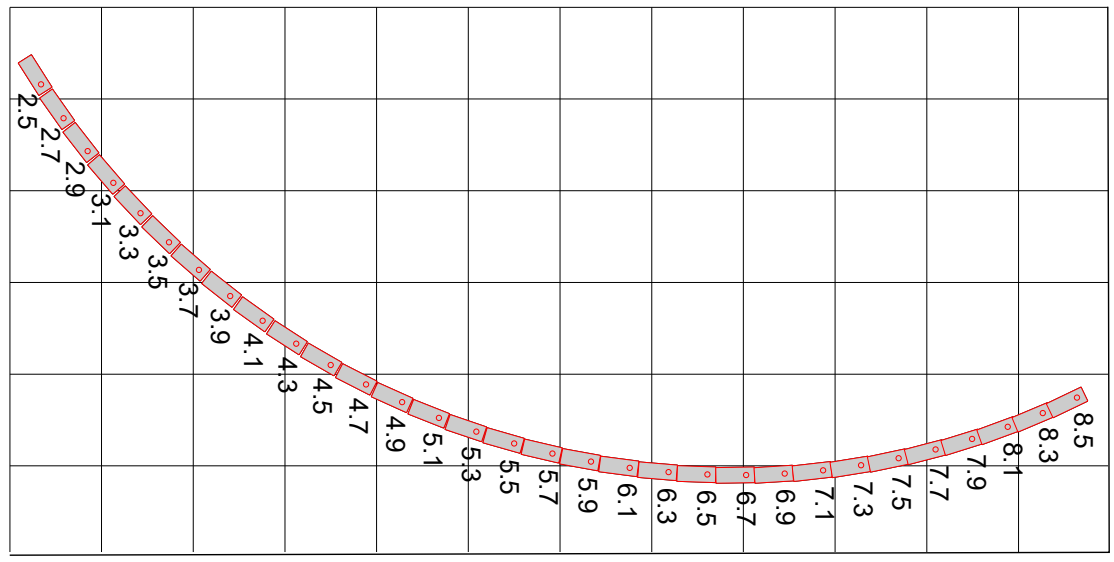

Figure 2.2: Vehicle original trajectory.

To demonstrate the vehicle's behavior when the wheels are locked in a turn, another two scenarios were simulated. The starting speed and steering wheel angle were the same as in the first simulation. The difference is that in these two new scenarios, braking inputs were applied in order to force the front and the rear wheels to lock. As expected, when the front wheels are locked, the vehicle follows a straight line path. This is not a desirable condition, but as soon as the driver releases the brakes, the capability to generate lateral forces is restored. When the rear wheels are locked, the vehicle spins. This is an undesirable condition, since it is much more difficult for a normal driver to bring the vehicle to a stable condition after locking the rear wheels. A graphical illustration of both situations is shown in Figure 2.3

Front Wheels Locked

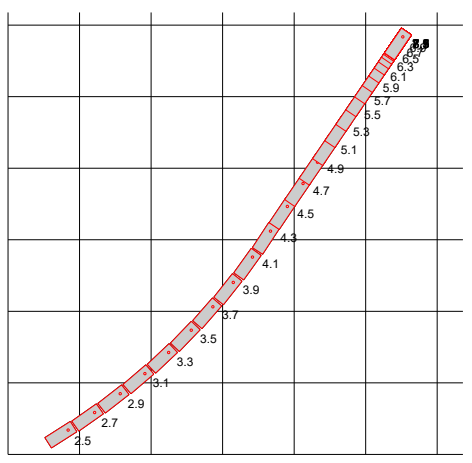

Rear Wheels Locked

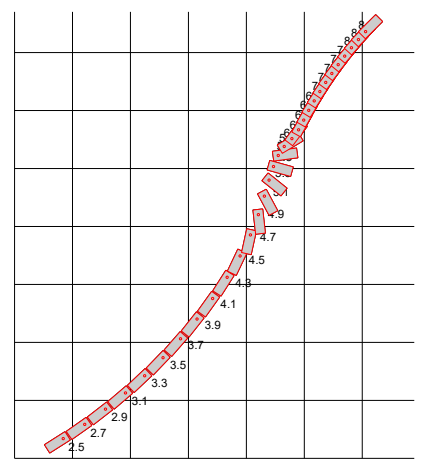

Figure 2.3: Locking front and rear wheels in a turn.

As a conclusion, these last two simulations helped not only to demonstrate the vehicle's behavior when the wheels are locked in a turn, but also 
to support the real importance of having a vehicle equipped with ABS. The main purpose of this system is not to stop the vehicle in a shorter distance, but always avoid locking the wheels in order to keep the vehicle in a stable condition. In vehicles without ABS, valves are installed to limit the oil flow to the rear wheels, this solution leads to a fixed braking force distribution where normally only $30 \%$ of the brake pressure is delivered to the rear axle. This distribution is not optimized for low deceleration braking maneuvers, what may lead to a poor performance when the vehicle is braking in low friction surfaces. The ABS system automatically distributes the braking force on each wheel in order to get an optimized braking force for each acceleration. More information about setting an optimized braking distribution can be found in (30). 


\section{3}

\section{Vehicle Lateral Dynamics}

Following the same approach of Chapter 2, this section will analyse a very simple model of lateral dynamics in order to make clear what are the force generation limits for each vehicle. The generation of lateral forces is limited by the same factors of the longitudinal ones. In theory, a passenger car should reach the friction limit at $\frac{\dot{v}}{g}=1$, what does not happens in the practice, once the lateral forces deforms the tire and reduces the capability of force generation.

In some cases, there is a possibility of a vehicle rollover instead of sliding, this condition occurs when the vehicle reaches the lateral tilting limit. This behavior can be predicted by making a simple torque balance using the force diagram shown in Figure 3.1.

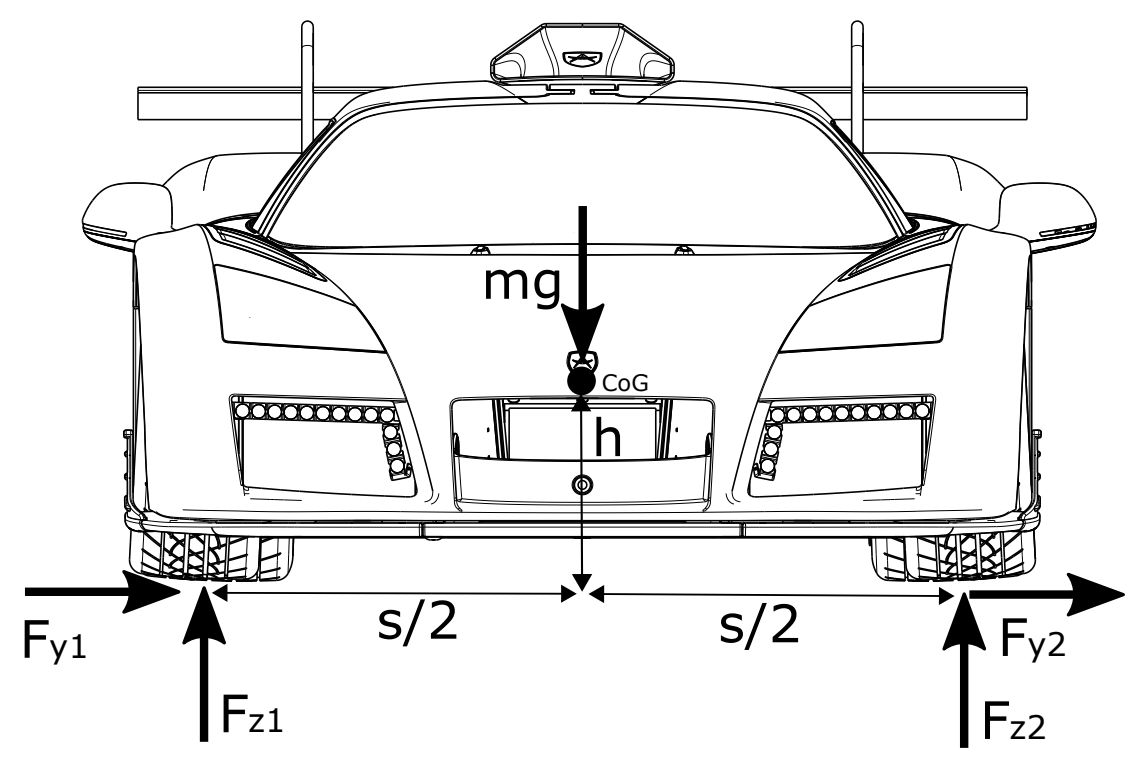

Figure 3.1: Lateral forces acting at the vehicle.

Considering the line which connects the two outer wheels' contact points as reference, the torque balance around this axis will be

$$
m g \frac{s}{2}-m a_{y} h=0
$$

Solving Equation 3-1 for the lateral acceleration, the overturning limit can be expressed as 


$$
\frac{a_{y}}{g}=\frac{s / 2}{h}
$$

where the term on the right side of Equation 3-2 is also known as the static stability factor $\left(s_{F}\right)$. For a road with $\mu=1$ for example, a stability factor smaller than 1 means a high risk of rollover. To demonstrate the influence of the center of mass position at the rollover risk, steering wheel step simulations were done for a vehicle with different heights of the center of mass. The main objective is to show the amount of load change at the inside wheels during the turn. In this scenario, the vehicles are driving at $100 \mathrm{~km} / \mathrm{h}$ and a step input of 30 degrees is made at the steering wheel. The results are show in Figure 3.2.

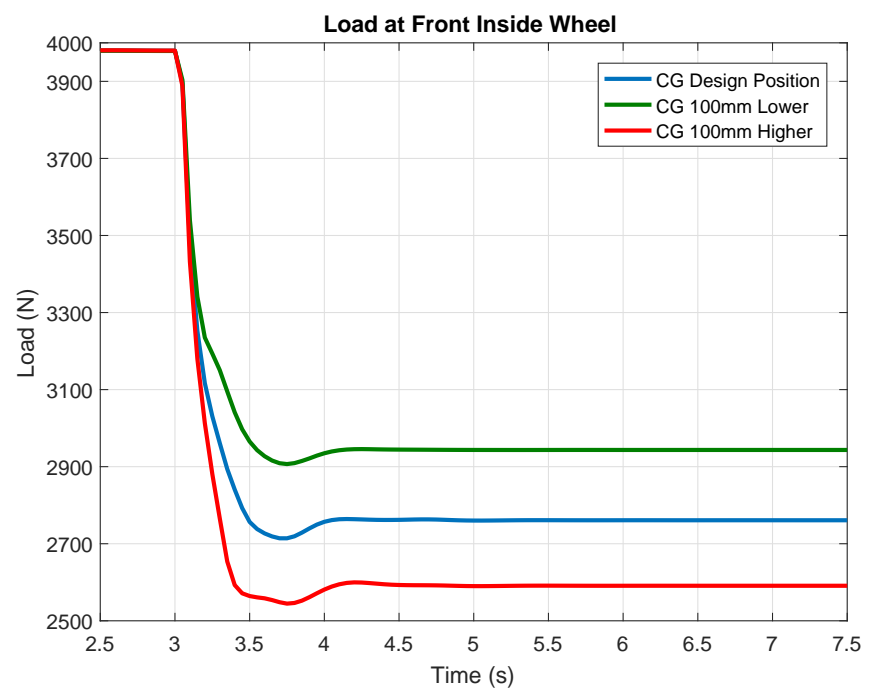

Figure 3.2: Loads at the front inside wheel during a turn.

This simple theory was applied in order know which behavior will be the limiting factor to consider while developing the control system. The results for each vehicle are shown in Table 3.1.

Table 3.1: Vehicle parameters and overturning limits.

\begin{tabular}{|l|c|c|c|c|}
\hline Parameters & $\mathrm{s} / 2[\mathrm{~m}]$ & $\mathrm{h}[\mathrm{m}]$ & Friction $[\mu]$ & Overturning $\left[a_{y}^{\max } / g\right]$ \\
\hline Mid-size & 0.75 & 0.54 & 1 & 1.5 \\
\hline Full-size & 0.76 & 0.57 & 1 & 1.3 \\
\hline Apollo N & 0.83 & 0.37 & 1.2 & 2.4 \\
\hline
\end{tabular}

The obtained values for overturning were higher than the tire friction limit, which means that the vehicle will enter in a sliding condition instead of rolling over. It is important to mention that this calculation did not consider the downforces, which will provide a considerable improvement on the overturning and friction limits. This simple analysis made possible to simplify 
a future rule base when designing the Fuzzy controller, as soon as the rollover possibility will not be considered.

\section{1}

\section{Steering Tendency}

The steering tendencies are possible characteristics that a vehicle can assume when making a turn. The steering angles on both wheels for a vehicle in a turn were calculated using the Ackerman's Geometry $(30,16)$. If the vehicle is able to make a turn with radius $R$ using the same steering angle predicted by the Ackerman's Geometry, then this vehicle is called neutral. This behavior does not occur in practice, but it serves as a reference for comparing with the two real behaviors of a vehicle.

If the required steering input for making a turn is greater than the Ackerman's angle, then the vehicle has an understeering characteristic. On other hand if this input is smaller than the theoretical value, this vehicle has an oversteering tendency. Street cars should have an understeering behavior, since the nature of normal drivers tells them to increase the steering angle in a turn in case of an unexpected trajectory. The same assumption does not work for sportive and race cars, which most of the times have oversteering characteristics in order to allow the driver to make turns with smaller radii. Figure 3.3 shows a step input simulation, made in order to demonstrate these differences of behavior.

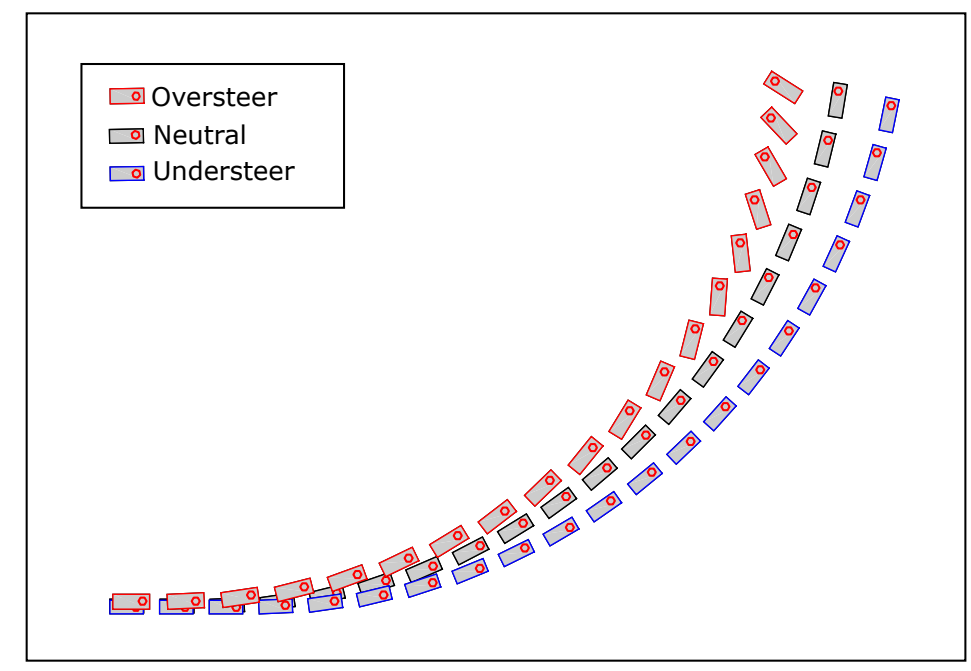

Figure 3.3: Different driving tendencies for a vehicle.

After analysing the simulation, it is noticeable that for the same input, an understeering vehicle drives through a higher radius compared with the other ones. When the vehicle has an oversteering characteristic, this radius 
is smaller and a larger yaw motion is noticed. Considering high speeds, the necessary steering angle for drive through a turn with radius $R$ is defined by

$$
\delta=\frac{a_{1}+a_{2}}{R}+m \frac{v|v|}{R} \frac{a_{2} c_{s 2}-a_{1} c_{s 1}}{c_{s 1} c_{s 2}\left(a_{1}+a_{2}\right)},
$$

where the first part of Equation 3-3 is the steering angle provided by Ackerman's geometry, $c_{s 1}$ and $c_{s 2}$ are the cornering stiffness at the front and the rear axles and $a_{1}$ and $a_{2}$ are the distances between the axles and the center of mass. Once the lateral acceleration is $a_{y}=\frac{v|v|}{R}$, this equation can be re-written as

$$
\delta_{0}=\delta_{A}+k a_{y}
$$

where the steering gradient $(k)$ will determine an understeering, neutral or oversteering tendency. If a linear model (29) is considered, the relation between the steering gradient and the driving tendencies can be clearly noticed, as shown in Figure 3.4.

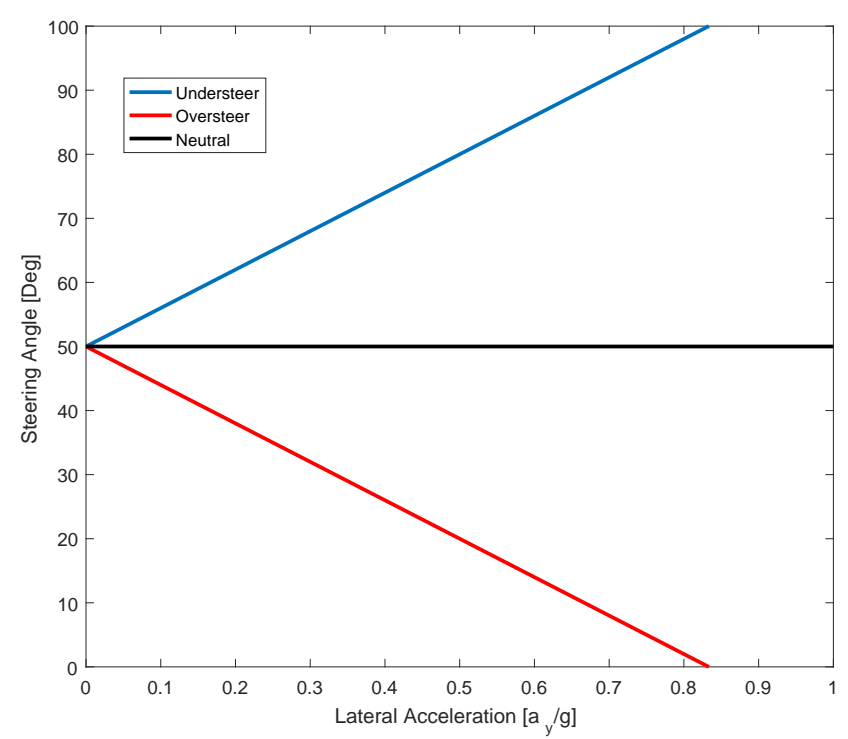

Figure 3.4: Steering gradients for a linear model.

As presented in Figure 3.3, for the oversteering case in particular, there is a possibility of spinning on z-axis. Once the steering gradient for this kind of vehicle has a decreasing behavior, it is possible that in special situations, the steering angle will be negative. This condition tells that in such cases, the driver must counter steer in order to keep the vehicle's stability.

In real vehicles or non-linear models, these behaviors are noticed in a different way. In order to demonstrate these characteristics, a steady-state cornering simulation was done. In this analysis, the vehicle drives through a circle with constant radius and the speed is slowly increased in order to increase 
progressively the lateral acceleration. The driving tendency is obtained by plotting the necessary steering angle to keep the vehicle at the circle for each lateral acceleration value, as done in Figure 3.5.

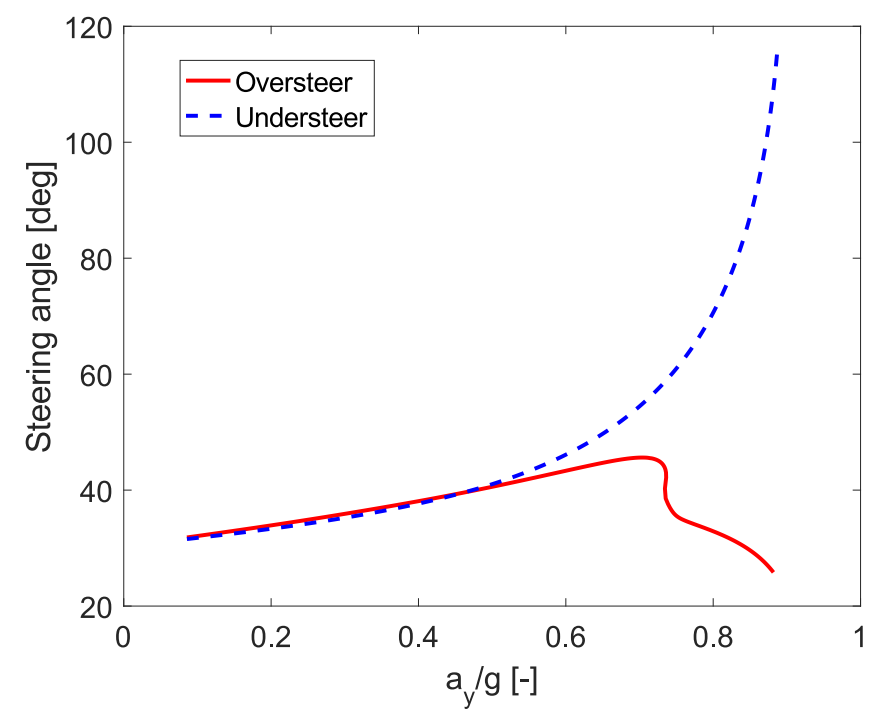

Figure 3.5: Steering gradients for a non-linear model.

Assuming that the vehicle has the same tires on each axle, the driving tendency was changed by increasing the rear anti-roll bar stiffness. This procedure will increase the cornering stiffness at the rear axle $\left(c_{s 2}\right)$ and result in an oversteering tendency. When the steady-state cornering plot is analyzed, two conclusions can be taken regarding the driving tendencies:

- For lower accelerations, the steering gradient in understeering vehicles is similar to the linear model. This behavior occurs because in small lateral accelerations, the tire is working in a linear range. Higher accelerations will generate larger slip values and bring the tire to a non-linear operating region. This condition will result in a non-linear increase of the steering gradient. The tire force generation characteristics will be further discussed in Section 4.1.

- In practice, it makes no sense to design a vehicle which has an oversteering tendency for any lateral acceleration value, once it means serious instability problems. In this simulation, the real behavior of an oversteering vehicle could be observed. The car has an understeering tendency until a critical lateral acceleration value is achieved. After that, the vehicle enters in an unstable condition, noticed by the steering wheel input after $\frac{a_{y}}{g}=0.7$. 
The studies done in this chapter helped to set up two main objectives for designing the autonomous steering controller. The most important is to guide the vehicle trough an avoidance maneuver without crossing the friction limits. The second one is to develop a controller which is able to handle vehicles with understeering and oversteering behaviors, once this characteristic can change depending on the situation. 


\section{4}

\section{Mathematical Model}

In this chapter, some of the concepts of the 3 -D vehicle model will be presented. The complete vehicle model was done using the theory of multi-body systems described in (31). Seventeen rigid bodies were considered: 4 wheels, 1 chassis and 4 double wishbone suspension systems, composed by 3 bodies each. The equations of motion were obtained by using the virtual power method (Jourdain's principle), where the constraint equations are used to determine the iteration forces between the bodies. From the Jourdain's formulation, a set of differential algebraic equations is obtained. These equations are grouped in three main parts, as shown in Equations 4-1, 4-2 and 4-3.

$$
\begin{gathered}
K(y) \dot{y}=z \\
M(y) \dot{z}=q(y, z, s, u) \\
\dot{s}=f(y, z, s, u)
\end{gathered}
$$

The first set of equations defines the system kinematics, where $y$ is the vector which contains all the generalized coordinates and $K(y)$ is the kimenatics matrix, used to define the vector of generalized velocities $z$. The second set defines the dynamics, once $M(y)$ is a mass matrix, $\dot{z}$ is the vector of accelerations and $q$ is a vector of generalized forces, which depends also on the inputs $u$ and aditional states stored in $s$.

\section{1}

\section{Wheels and Tires}

Tires are the interface between the vehicle and the environment. For this reason, a proper vehicle dynamics simulation must have an accurate tire model in order to validate any result from measurements done in a real car. This requires a special effort to be done, since the force generation is highly non-linear and the models are normally done based on acquired measurements. The Apollo N uses different tires in front and rear wheels. A pair of 285/30R19 tires are used at the front wheels and another two 345/30R20 tires are equipped at the rear. Based on experimental data acquired at the supplier's test rig, the 
force characteristics were evaluated and used as an input for the mathematical model.

\subsection{1}

\section{Longitudinal Slip and Force Generation}

The slip is a consequence of the tire force generation. When the vehicle is accelerating for example, the driven wheels' speeds are always greater than the vehicle's speed. The slip of a wheel is defined as a function of its tangential speed and the vehicle's velocity, as shown in Equation 4-4

$$
s_{x}=\frac{-\left(V_{x}-\Omega r_{D}\right)}{|\Omega| r_{D}+V_{N}},
$$

where $V_{x}$ is the longitudinal vehicle velocity, $\Omega$ is the wheel angular speed, $r_{D}$ is the tire dynamic radius and $V_{N}$ is a fictitious velocity, introduced to avoid numerical problems when the wheel is locked.

For small slip values, the relation with the generated force can be considered linear. After this small range, it grows in a non-linear way until the tire generates maximum adhesion force $\left(F_{x}^{M}\right)$. When the maximum force is reached, a greather torque coming from the engine or from the brakes will only increase the slip, what will bring the wheel to a full slide condition. The qualitative relation between slip and longitudinal force is shown in Figure 4.1, where the slope of the linear part is defined by the driving stiffness $\left(d F_{x}^{0}\right) . F_{x}^{M}$

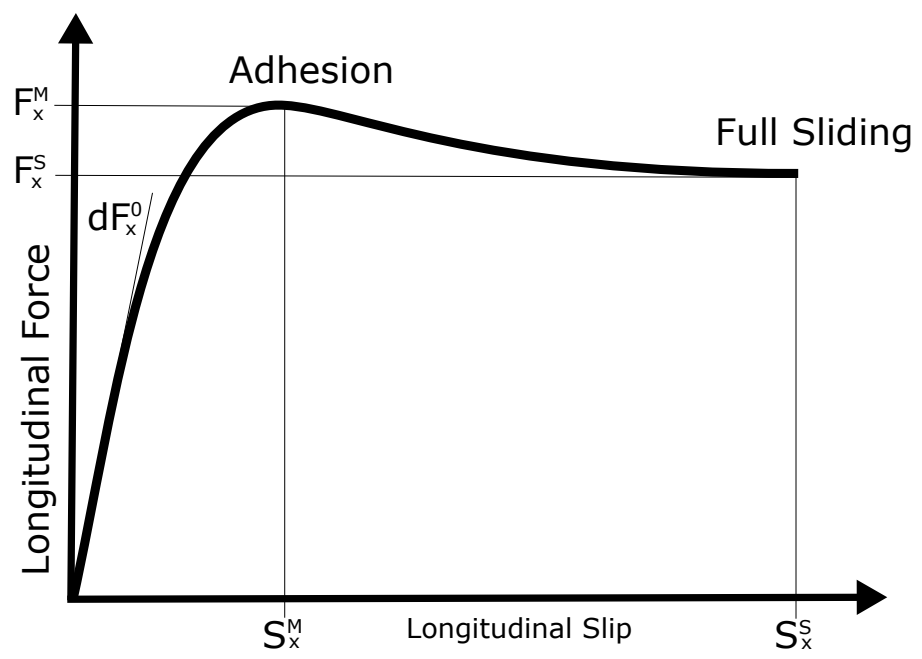

Figure 4.1: Tire force generation.

is the maximum adhesion force and it is associated with a slip value $s_{x}^{M}$ and $s_{x}^{S}$ is the point where the vehicle begins full sliding, which is associated with the force $F_{x}^{S}$. 


\subsection{2}

\section{Lateral Slip and Force Generation}

The qualitative aspect of the lateral force generation curve is the same as in Figure 4.1, but in this case the slope is called cornering stiffness $\left(d F_{y}^{0}\right)$. Instead of using the longitudinal speeds, the lateral slip is defined by Equation 4-5, where $V_{y}$ is the lateral speed of the vehicle.

$$
s_{y}=\frac{-V_{y}}{|\Omega| r_{\text {wheel }}+V_{N}}
$$

\subsection{3}

\section{Combined Lateral and Longitudinal Forces}

In normal driving situations, the vehicle has longitudinal and lateral slips at the same time. It must be considered that the generated force is a vector and its magnitude is composed by the lateral and longitudinal accelerations. The consideration of a generalized slip is important to define a combined force, where for example, the lateral forces produced by the tires in a turn will reduce the capabilities to generate longitudinal forces for braking. For modeling this condition, the slips can be combined as a simple vector addition with normalization

$$
s=\sqrt{\left(\frac{s_{x}}{\hat{s}_{x}}\right)^{2}+\left(\frac{s_{y}}{\hat{s}_{y}}\right)^{2}},
$$

where $\hat{s}_{x}$ and $\hat{s}_{y}$ are the normalizing factors for each slip, described by

and

$$
\hat{s}_{x}=\frac{s_{x}^{M}}{s_{x}^{M}+s_{y}^{M}}+\frac{F_{x}^{M} / d F_{x}^{0}}{F_{x}^{M} / d F_{x}^{0}+F_{y}^{M} / d F_{y}^{0}}
$$

$$
\hat{s}_{y}=\frac{s_{y}^{M}}{s_{x}^{M}+s_{y}^{M}}+\frac{F_{y}^{M} / d F_{y}^{0}}{F_{x}^{M} / d F_{x}^{0}+F_{y}^{M} / d F_{y}^{0}} .
$$

For avoiding the same numerical problems of Section 4.1.1, the virtual velocity was also introduced at the normalized slips

$$
\frac{s_{x}}{\hat{s}_{x}}=\frac{-\left(v_{x}-\Omega r_{\text {wheel }}\right)}{\Omega r_{\text {wheel }} \hat{s_{x}}+v_{N}} \quad \text { and } \quad \frac{s_{y}}{\hat{s}_{y}}=\frac{-v_{y}}{\Omega r_{\text {wheel }} \hat{s_{y}}+v_{N}} .
$$

The combined forces can be expressed by the same parameters used to define the longitudinal or lateral forces, as shown in Equations 4-10 to 4-14,

$$
\begin{aligned}
d F^{0} & =\sqrt{\left(d F_{x}^{0} \hat{s_{x}} \cos \phi\right)^{2}+\left(d F_{y}^{0} \hat{s_{y}} \sin \phi\right)^{2}} \\
s^{M} & =\sqrt{\left(\frac{s_{x}^{M}}{\hat{s_{x}}} \cos \phi\right)^{2}+\left(\frac{s_{y}^{M}}{\hat{s_{y}}} \sin \phi\right)^{2}} \\
F^{M} & =\sqrt{\left(F_{x}^{M} \hat{s_{x}} \cos \phi\right)^{2}+\left(F_{y}^{M} \hat{s_{y}} \sin \phi\right)^{2}}
\end{aligned}
$$




$$
\begin{aligned}
s^{S} & =\sqrt{\left(\frac{s_{x}^{S}}{\hat{s_{S}}} \cos \phi\right)^{2}+\left(\frac{s_{y}^{S}}{\hat{s_{y}}} \sin \phi\right)^{2}} \\
F^{S} & =\sqrt{\left(F_{x}^{S} \hat{s_{x}} \cos \phi\right)^{2}+\left(F_{y}^{S} \hat{s_{y}} \sin \phi\right)^{2}}
\end{aligned}
$$

where the angle $\phi$ is defined by

$$
\sin \phi=\frac{s_{x} / \hat{s_{x}}}{s} \quad \text { and } \quad \cos \phi=\frac{s_{x} / \hat{s_{x}}}{s} .
$$

The three-dimensional composition with the longitudinal and lateral forces is illustrated in Figure 4.2.

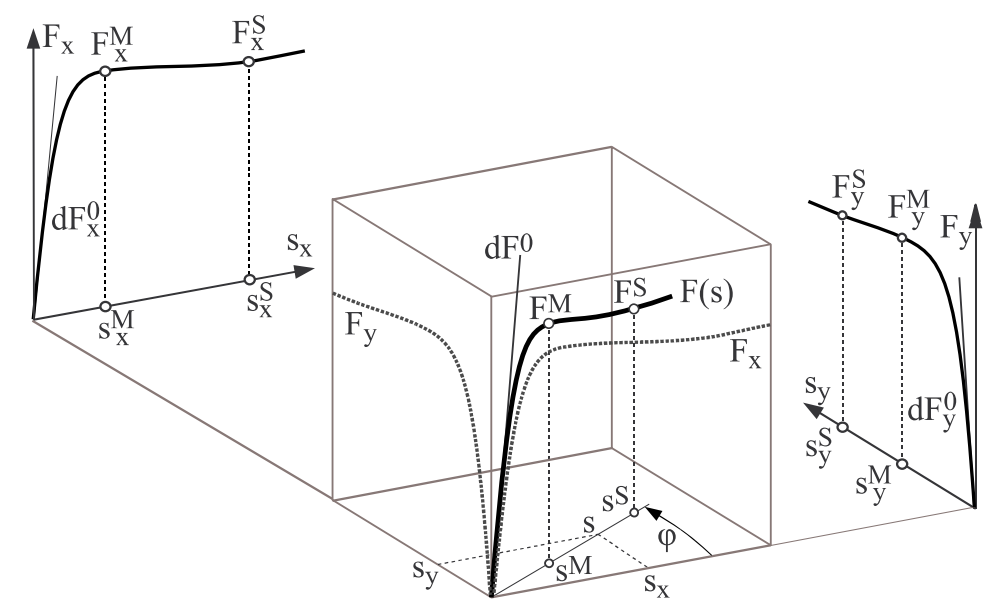

Figure 4.2: Combined tire force generation. Taken from (30)

The TMEASY model was used for modeling the tire-road iteration. It is used in a large range of commercial softwares and it is being developed and validated for a long time. It provides accurate results with a short calculation time, which means a significant performance improvement when simulating a complex 3-D non-linear vehicle model. More specific information about the TMEASY can be found at (32) and (13).

\section{2}

\section{Suspension}

The Apollo $\mathrm{N}$ uses a double wishbone suspension system equipped with push rods. This geometry is characterized by two control arms fixed by spherical joints in two points at the chassis and in one point at the wheel hub. This assembly still has a degree of freedom which allows the wheel to turn around the kingpin line. For this reason the introduction of a track rod is necessary. At the rear suspension, this element is used just for avoiding an undesirable toe change at the wheels. At the front, this bar is attached to the steering system and used as a command for steering the wheels. Only a short description of this suspension geometry will be done in this work, since more 
detailed information about modeling aspects can be found at (30) and (21). A simplified illustration of the suspension system is shown in Figure 4.3.

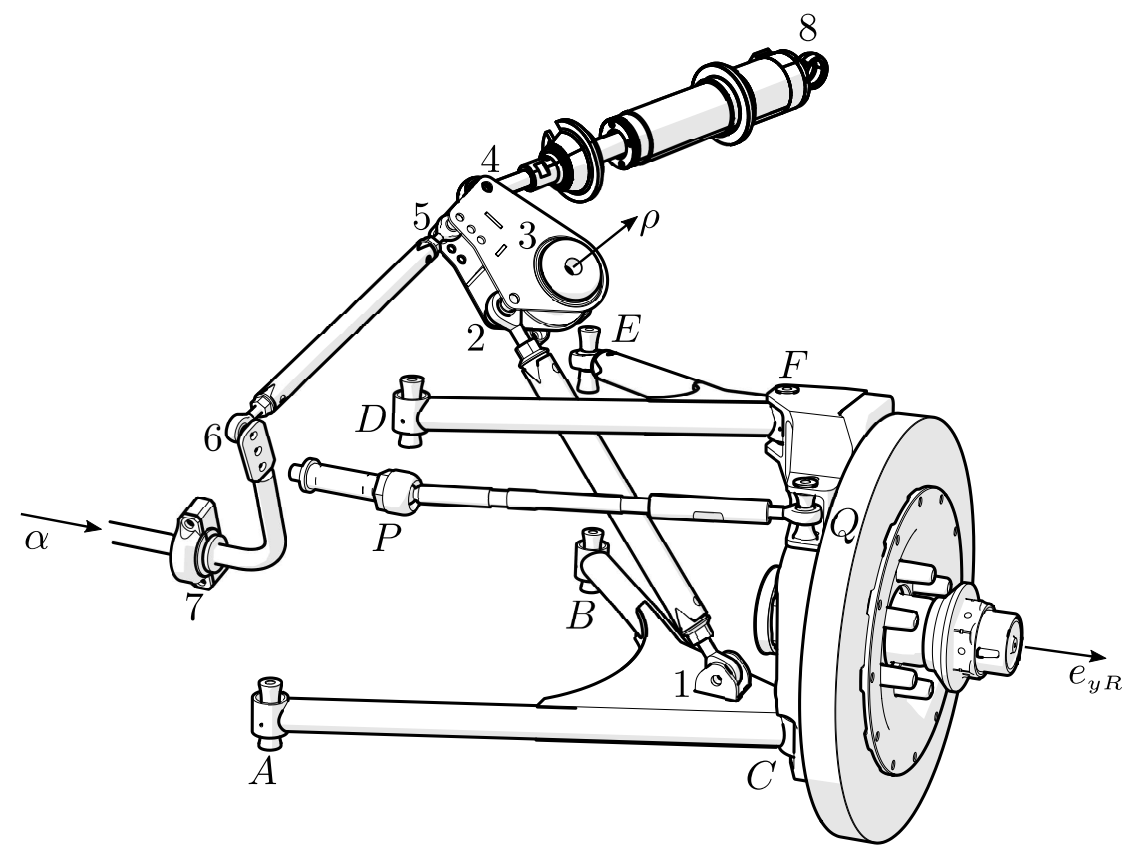

Figure 4.3: Double wishbone suspension with push rod system.

The positions of the whole system are defined by taking the rotation angle of the lower whisbone as reference. The points $A, B, D$ and $E$ are fixed with relation to the system placed at the vehicle's axle. The positions of $C$ and $F$ are defined using a simple description of rotation in space, as shown in Equations 4-16 and 4-17

$$
\begin{gathered}
r_{0 C, 0}=r_{0 A, 0}+A_{0 A} r_{A C, A}, \\
r_{0 F, 0}=r_{0 A, 0}+A_{0 A}\left(A_{A C} r_{C F, C}\right),
\end{gathered}
$$

where 0 is the reference system fixed at the axle, $A_{0 A}$ defines the rotation of the lower wishbone. The product $A_{0 A} A_{A C}$ stores the toe, kingpin and caster angles, defined by the positions of $C, F$ and $Q$. The inboard kinematics is defined by the push rod ( 1 and 2$)$, which is connected to a rocker that rotates at the axis $\rho$. The damper ( 4 and 8 ) and the anti-roll bar (5,6 and 7 ) are also attached to the rocker.

Some racing cars have a third damper element connecting the suspension systems of both sides, this is not the case of the Apollo. For this reason, the outboard kinematics was modeled in the same way of a normal double wishbone for a passenger car. The only difference was related to the inboard kinematics, once the presence of the rocker established a non-linear relation between the wheel travel and spring displacement. 


\section{3}

\section{Aerodynamics}

The aerodynamic forces are the main resistance to consider when estimating the top speed of a vehicle. These forces grows with the square of the velocity and can be modeled as

$$
F_{\text {aero }}=\frac{1}{2} \rho A_{\text {ref }} C v^{2},
$$

where $\rho$ is the air density, $A_{\text {ref }}$ is a reference area, $C$ is a non-dimensional coefficient and $v$ is the relative speed between the vehicle and the airflow. These forces can be decomposed in longitudinal and vertical components.

The component at the longitudinal direction is called drag. Equation 418 can be used to estimate the drag force by using the vehicle's frontal area as reference and the drag coefficient $\left(C_{x}\right)$ as the aerodynamic coefficient. The vertical component is called downforce, which can be neglected in most of series vehicles, but considering that the Apollo $\mathrm{N}$ can reach more than $300 \mathrm{~km} / \mathrm{h}$ and its bodywork was developed for generation high amounts of downforce, this component must be considered in the model. The downforce can be modeled as the same way of the drag, but in instead of using the drag coefficient $\left(C_{x}\right)$, the downforce coefficient $\left(C_{z}\right)$ must be used.

The downforces were measured for the first time in a test done by Michelin in 2009. The vehicle was put in a wind tunnel and the forces were measured at front and rear axles for a range of speeds from 0 to $360 \mathrm{~km} / \mathrm{h}$. The test considered four different angles of attack of the rear wing and one fixed position at front wing. The results of this measurement are shown in Figure 4.4. Later on, straight line tests were done in 2016 in order to confirm the measurements.

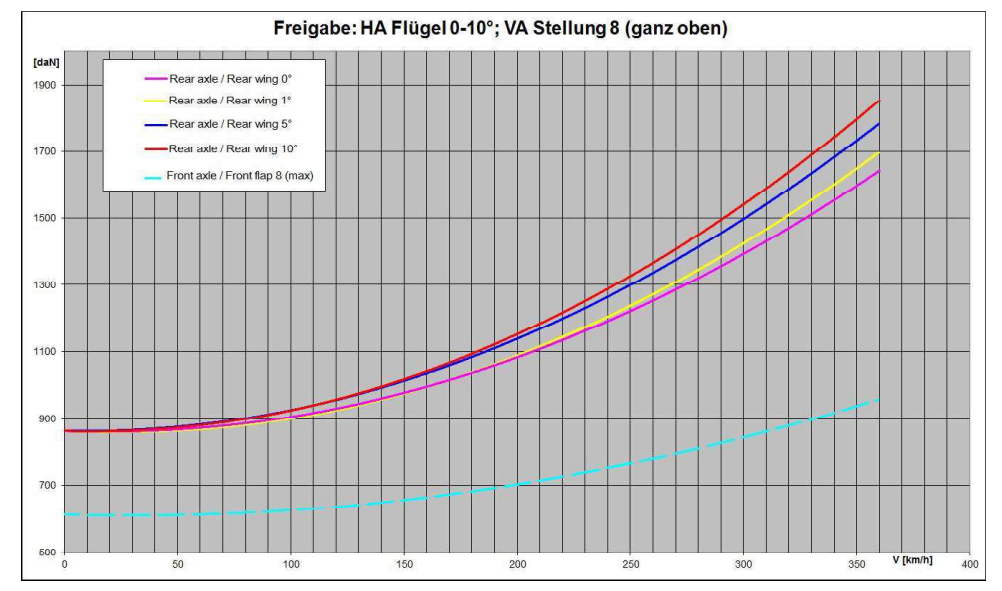

Figure 4.4: Measured downforces on each axle.

The Apollo has a static load distribution of $600 \mathrm{~kg}$ at the front and 
$900 \mathrm{~kg}$ at the rear. The values measured in the wind tunnel and in the straight line tests were taken into account to build a lookup table in order to model the downforces depending on the vehicle speed and the ride height. At both experiments, the drag coefficient was measured.

As said before, this vehicle was developed to generate high amounts of downforce. As a consequence, the estimated drag coefficient was very high. This characteristic is justified by the presence of aerodynamic appendices at the bodywork. On other hand, Table 4.1 shows that at $360 \mathrm{~km} / \mathrm{h}$, the car has almost $3,3 \mathrm{kN}$ more load at the front wheels and $9,6 \mathrm{kN}$ at the rear. This load increase represents significant earnings at the maximum tire force generation, as discussed in Chapter 2.

Table 4.1: Results of Downforce measurement.

\begin{tabular}{|c|c|c|}
\hline & Front Axle & Rear Axle \\
\hline Static Load & $600 \mathrm{~kg}$ & $900 \mathrm{~kg}$ \\
\hline Load @ $200 \mathrm{~km} / \mathrm{h}$ & $700(+100) \mathrm{kg}$ & $1170(+270) \mathrm{kg}$ \\
\hline Load @ $360 \mathrm{~km} / \mathrm{h}$ & $930(+330) \mathrm{kg}$ & $1880(+980) \mathrm{kg}$ \\
\hline
\end{tabular}

For modeling aspects, the downforces were divided equally between both sides of the vehicle. The drag force is applied at the vehicle's center of pressure and the downforces are computed by increasing the load on each wheel individually. The torques generated from the aerodynamic forces are described as

$$
M_{a e r o, F}=\left(\sum_{i=1}^{4} F_{z i} \times r_{0 i, F}\right)+F_{x} \times r_{0 C P, F},
$$

where $F_{z i}$ is the downforce at the wheel, $r_{0 i, F}$ the distance between the contact point and the fixed coordinate system, $F_{x}$ is the drag force and $r_{0 C P, F}$ the distance between the center of pressure and the fixed coordinate system.

\section{4}

\section{Drive and Brake Forces}

The investigations related to this work does not require a detailed power train model. For this reason, the driving torque was modeled as a simple torque output at the wheels. This torque output is performed by a PI controller, which provides it based on the actual speed error and the maximum available torque, defined in a lookup table.

The brake torques were modeled using the concept of Enhanced Brake Torque Model, presented on (30). This model was proposed in order to avoid numerically undesirable conditions present at the simple dry friction model, 
where there is a discontinuity when the wheel speed is equals to zero, as illustrated in Figure 4.5.

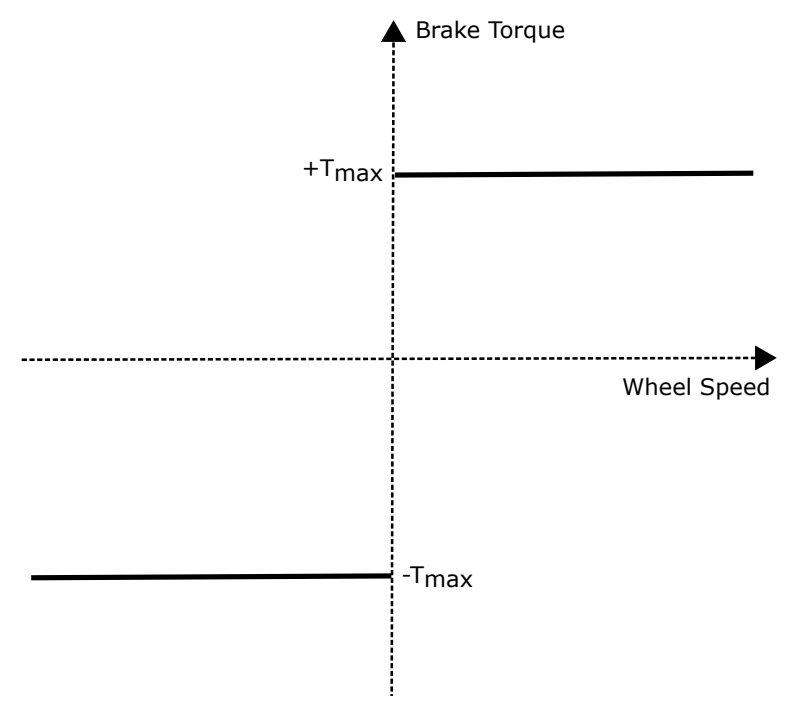

Figure 4.5: Simple dry friction model.

This discontinuity brings big disadvantages. Once the braking torque is not defined in this point, it will create jumps at the force output, make the integration time longer and the result less precise. Another problem is a lack of definition for braking torque when the wheel is locked. At the Enhanced Brake Model, the maximum braking force is not available instantly. It was modeled as linearly dependent from the wheel speed to avoid the mentioned jumps at force output. A constant braking torque for zero wheel speed was also introduced in order to provide a constant brake torque for a locking wheel. The behavior of the enhanced braking model is illustrated in Figure 4.6.

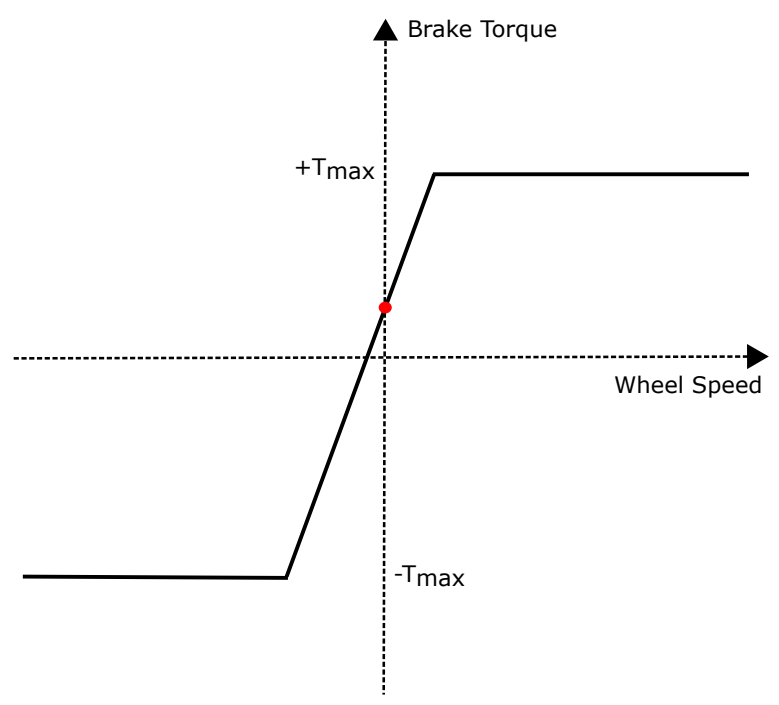

Figure 4.6: Enhanced Braking Model. 


\section{5}

\section{Fuzzy Control}

A Fuzzy control system was developed to manage the vehicle's braking steering inputs. These systems are based on a rule base and uses the level of activation of each rule to infer about an appropriate decision for the given situation. This control strategy was chosen because of its simplicity and effectiveness while dealing with non-linear systems. The basis of this theory is being developed since four decades ago (38).

\section{1}

\section{Time to Collision}

The concept of time-to-collision is used to determine if the driver is able to manage a dangerous situation, or if the system must actuate in order to avoid an accident. This variable allows to know how much time the vehicle would take to collide with an obstacle. This situation is described in (23) by Equation 5-1.

$$
T T C=\frac{\Delta L}{v_{r e l}},
$$

Where $\Delta L$ is the distance and $v_{r e l}$ is the relative velocity between the vehicle and the obstacle. Assuming that a driver takes up to 1.5 seconds to react (12), the system must actuate every time that $T T C \leq 1.5$, in order to avoid or mitigate the collision.

\section{2}

\section{Braking Control}

In Chapter 2 it was shown that the ABS system is responsible for keeping the vehicle's stability. Once it is impossible to have a real time measurement of the friction coefficient, the controller must find an alternative way to detect that a wheel is about to lock. In theory, the slip of each wheel should be measured in order to detect it is close to a locking situation. Despite being used as a basis for commercial systems, the slip estimation is not precise, once the measurement of vehicle's longitudinal speed requires very expensive sensors, not present in most of the passenger cars. In some commercial systems, 
the wheel angular speeds are measured and compared in order to detect if one wheel is rotating slower than the others.

As said in the beginning, one of the objectives of this work is to implement and demonstrate the concepts in a simple way. The vehicle's longitudinal speed is determined by a mean of the four wheels' tangential velocities. This measurement will be compared with the individual wheel speed and used to estimate and control the wheel slip. This approach was possible because on its essence, fuzzy systems are developed to handle imprecisions. Also known as "specialist systems", if the process is deeply known and the linguistic therms are well defined, measurement imprecisions and non-linearities can be overcome.

The ABS controller could be defined by using only three fuzzy rules (Table 5.1), what demonstrates the controller's power when managing a highly non-linear system. Another advantage is related to the imprecision associated to fuzzy systems. Normally, the point of maximum force for passenger cars occurs at $10 \%$ of slip, but this value changes according the rubber compound. The objective of the ABS controller is to keep the slip in a "MEDIUM" value, since zero slip means no force generation and high slips means full sliding.

Table 5.1: Fuzzy control rules for the ABS system.

\begin{tabular}{|l|c|}
\hline Slip & Brake Torque \\
\hline Low & High \\
\hline Medium & Medium \\
\hline High & Low \\
\hline
\end{tabular}

In preliminary simulations, the mid-size and full-size vehicles were used in order to test the fuzzy controller's effectiveness. For both vehicles, the controller was able to manage braking maneuvers without locking the wheels for friction coefficients down to $\mu=0.3$. As expected, the same controller was able to handle different passenger cars with different tires compounds using the fuzzy sets shown in Figure 5.1.

In oder to illustrate the controller's behavior, a simulation was made with the mid-size braking in a road with $\mu=0.5$, which is equivalent to a wet road. The Figure 5.2 shows a comparison between the vehicle's and wheels' speeds.

Besides not locking any wheel, an ABS system must show a reasonable performance. The effectiveness of the ABS control was tested by comparing the output of longitudinal acceleration with the track friction limits. When actuating, the ABS system produces a high-frequency acceleration output due the continuous procedure of braking and releasing the wheels. Despite this behavior, it can be noticed on Figure 5.3 that the longitudinal acceleration was very close to the track's friction limit. 

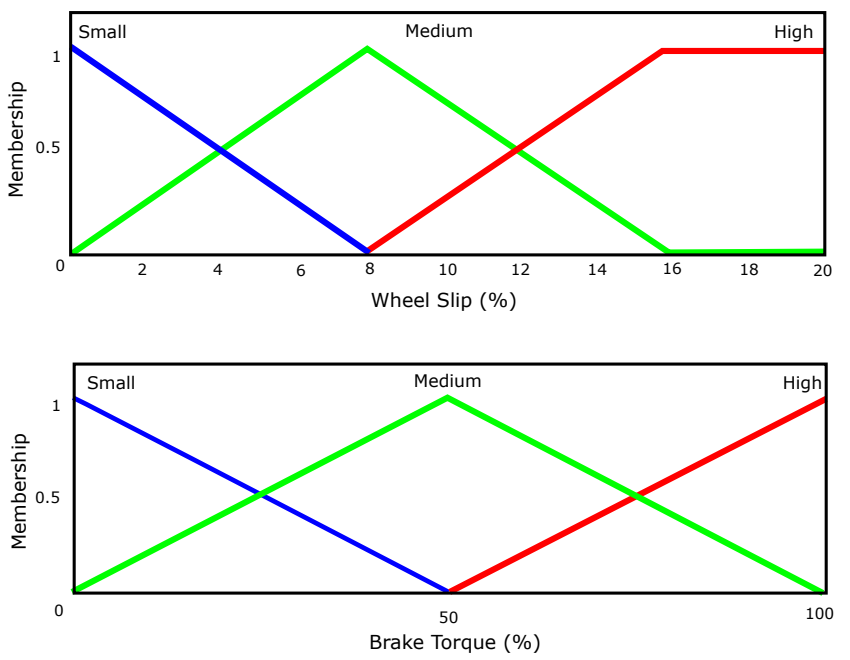

Figure 5.1: Input and output fuzzy sets.

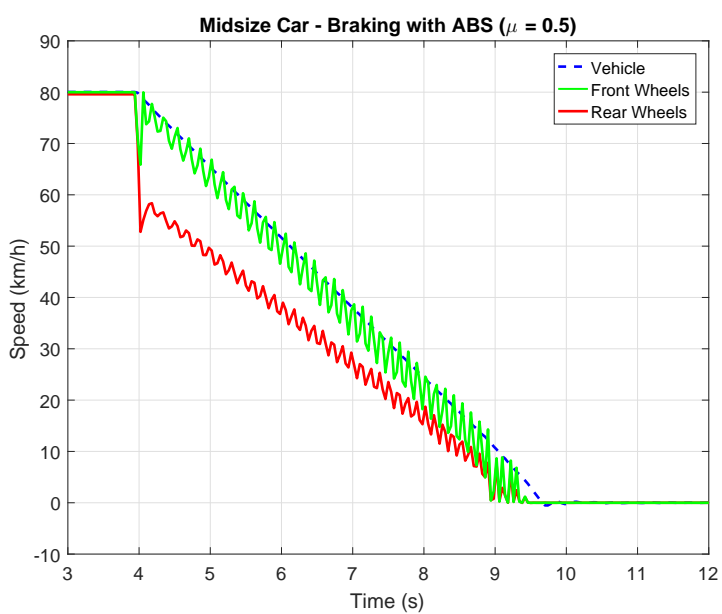

Figure 5.2: Vehicle Longitudinal speed compared to front and rear wheels' speeds.

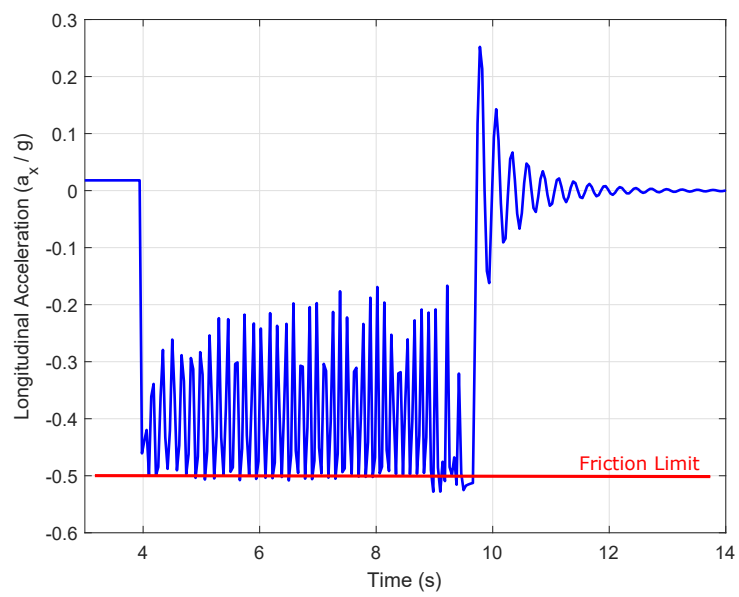

Figure 5.3: Vehicle Longitudinal Acceleration. 


\section{3}

\section{ABS Adaptation for the Apollo N}

To work with the Apollo N, the slip linguistic definitions must be modified. This procedure was necessary once this car uses special tires which can reach the maximum forces at a considerably small slip value. The cornering stiffness is also higher than in a normal car, which means a stronger growth of force at low slips. Taking these particularities into account, the slip values for these tires was considered "LOW" for values between 0 and 2\%, "MEDIUM" for values around $2 \%$ and "HIGH" for slips larger than $4 \%$. The braking torque was also defined as "LOW", "MEDIUM" and "HIGH". The new input fuzzy sets are shown in Figure 5.4.

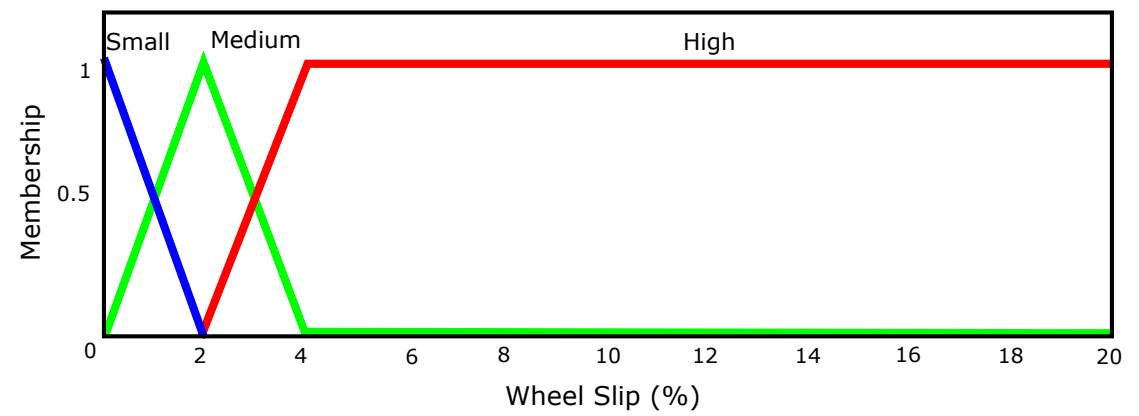

Figure 5.4: Input fuzzy sets for the Apollo tires.

After this modification, a braking maneuver at $90 \mathrm{~km} / \mathrm{h}$ was simulated in a track with the standard friction coefficient. The first impression of the controller's performance was satisfactory, once the vehicle was close to the acceleration limit and kept it during all the maneuver, as shown in Figure 5.5.

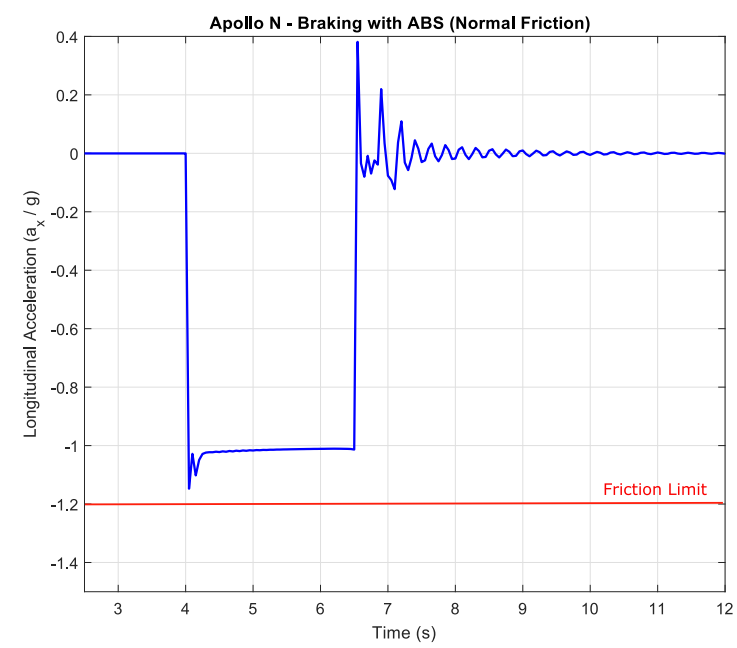

Figure 5.5: Longitudinal acceleration output at the Apollo $\mathrm{N}(\mu=1.2)$. 
The friction limits are reached when the wheels are being braked in an optimum slip range or in some cases, when they are locked and the vehicle is in a full sliding condition. For this reason, the wheel speeds must be checked in order to conclude if the system had a good performance or if all the wheels were locked. Figure 5.6 shows the comparison between the wheels' and vehicle's speeds. During the maneuver, the wheel speeds were very close to the vehicle speed. This behavior means a very good performance at a dry road, once the slips were small and consequently, the risk of locking a wheel was very low.

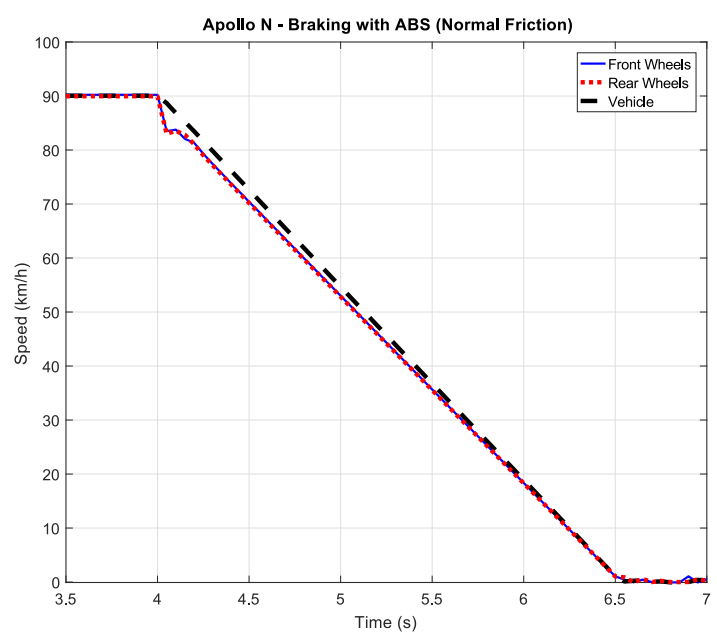

Figure 5.6: Comparison between wheels and vehicle's speeds at the Apollo N.

After testing the controller in a normal friction track, another simulation was done in order to analyze the performance in low friction conditions. The scenario was built considering a flat road with $\mu=0.5$. This simulation scenario with such a low friction coefficient is comparable with braking the vehicle in considerably wet track conditions, as Table 5.2 shows.

Table 5.2: Typical friction coefficients for different roads.

\begin{tabular}{|c|c|}
\hline Road type & Friction coefficient \\
\hline Dry & 1.0 \\
\hline Wet & 0.6 \\
\hline Snow & 0.2 \\
\hline Ice & 0.05 \\
\hline
\end{tabular}

Making the same inspection done in Figure 5.6, it is possible to see that even in a low friction condition the fuzzy controller was able to perform the braking maneuver and keep vehicle's stability. On other hand, the performance was considerably lower compared to the system implemented at the passenger cars. Figure 5.7 shows the simulation outputs of speeds and longitudinal acceleration. 

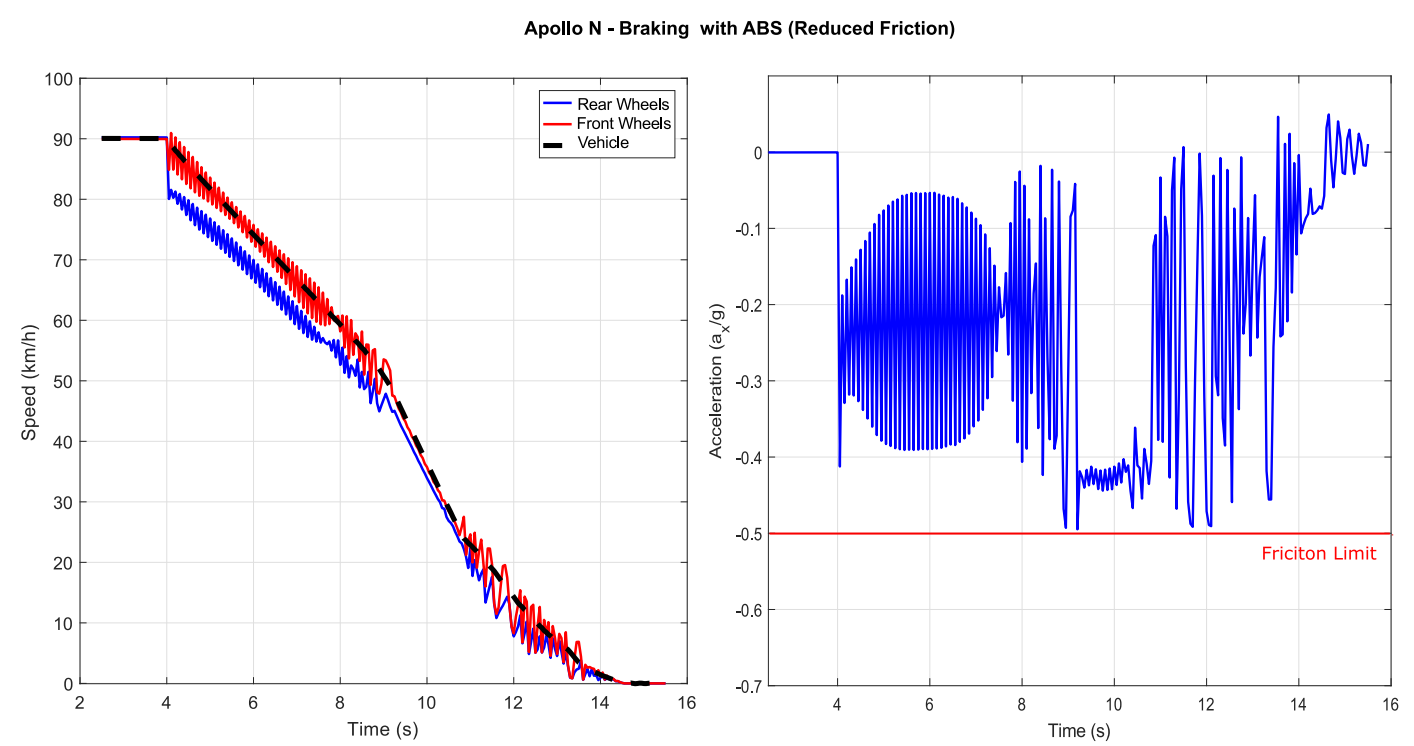

Figure 5.7: Simulation outputs for braking in reduced friction conditions $(\mu=0.5)$.

At the Apollo N, the ABS system had a good performance when simulated in a dry road. In low friction conditions, the system was able to perform the maneuver but the braking performance was not adequate for an emergency situation. This behavior was not observed at the normal passenger car because of the smaller tire cornering stiffness. Due to the special tires, which provides a huge force response to a small slip variation, one of the common problems of ABS controllers was noticed: The instability in low friction conditions. This problem can be explained by analyzing the typical behavior of the Apollo's tires. Assuming that the point of maximum force $\left(F^{M}\right)$ occurs when the slip $\left(s_{x}\right)$ is around $5 \%$, the operation range of an ABS system can be divided in two main regions, as shown in Figure 5.8.

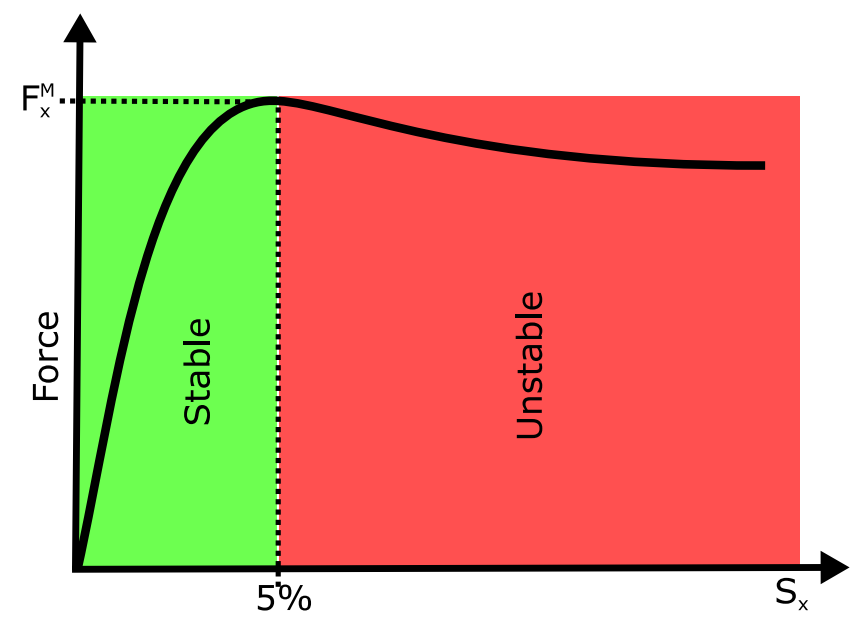

Figure 5.8: Working ranges for an ABS controller.

For slips smaller than 5\%, the ABS system will work in a stable region. 
In this range, an increase at the slip will result in more force generation, what is a desirable working condition. For higher slips, the tire enters in a saturation region where the forces reached the limit and the wheels will be about to enter in a full sliding condition. Working in this region is highly undesirable, but in lower friction conditions, the slips increases more sensitively and most of the times the ABS controllers are forced to operate in this unstable range.

Figure 5.9 shows a plot of the slips during the baking maneuvers in each scenario. For normal friction, the slips of the front and rear wheels are kept at $4 \%$ and $3 \%$ respectively. In this condition, the ABS controller is working on the stable range, which is located before the point of maximum force. This explains also why the friction limits where not reached and the acceleration output was almost constant. This behavior does not happen in the low friction scenario, where specially the front wheels' slips are easily reaching $10 \%$, bringing the controller to an unstable region, where it is easier to lock the wheels.

In these extreme conditions, the commercial ABS controllers tends to enter in an oscillatory behavior, which can be noticed by oscillations at the brake pedal. Some solutions are implemented to solve this problem, for example, using different speeds for increasing and decreasing the brake torque. As said in the beginning of this work, the main intention is not to reinvent the ABS system, but to have a controller with a suitable performance which can be used together with an autonomous collision avoidance system. Furthermore, in the normal passenger cars, the ABS fuzzy controller still has a good performance, which means that it can be used in considerable range of vehicles.
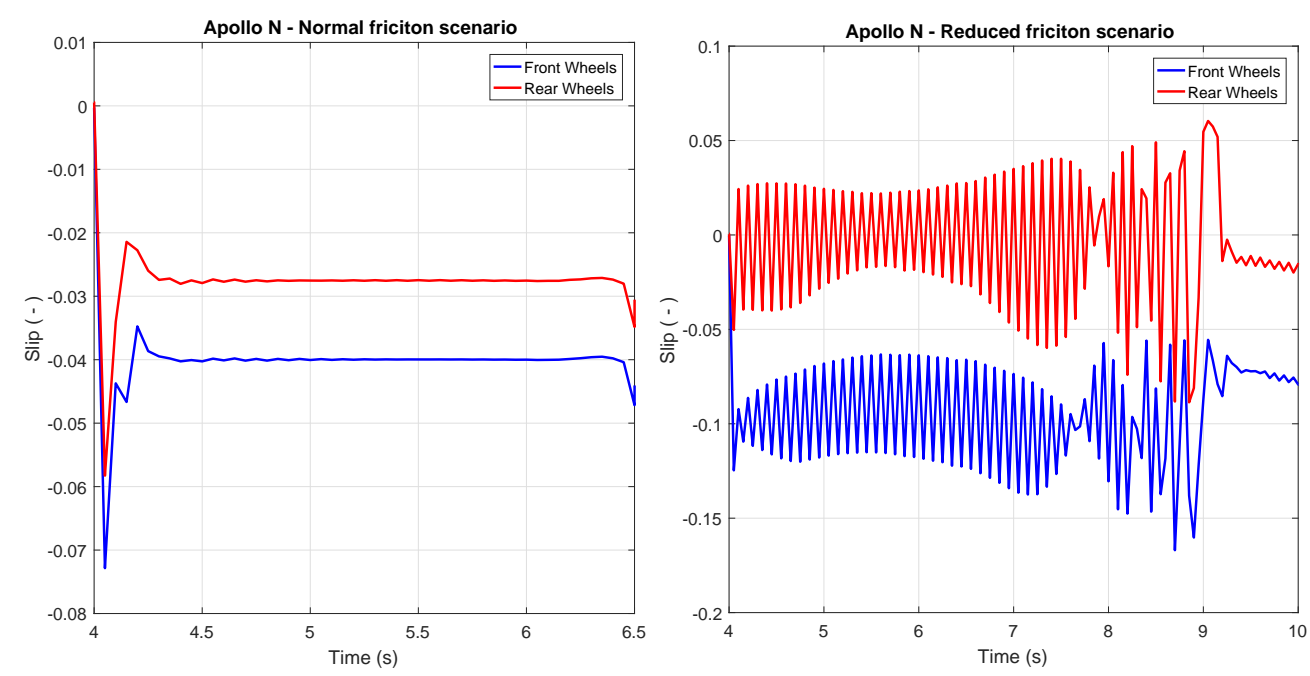

Figure 5.9: Slip variation during braking maneuvers. 


\section{4}

\section{Autonomous Braking Maneuver}

The final simulation for the fuzzy ABS controller is the autonomous braking maneuver. In this scenario, an obstacle was placed at the track and the time-to-collision was used as a reference to trigger the autonomous braking system. The Apollo $\mathrm{N}$ has an initial speed of $100 \mathrm{~km} / \mathrm{h}$ and the friction conditions were normal. The outputs of longitudinal acceleration and distance to the obstacle will be analyzed in order to detect if the system was able to stop the vehicle or if there was a collision, which would generate a longitudinal acceleration much larger than the friction limits. The results are shown in Figure 5.10.

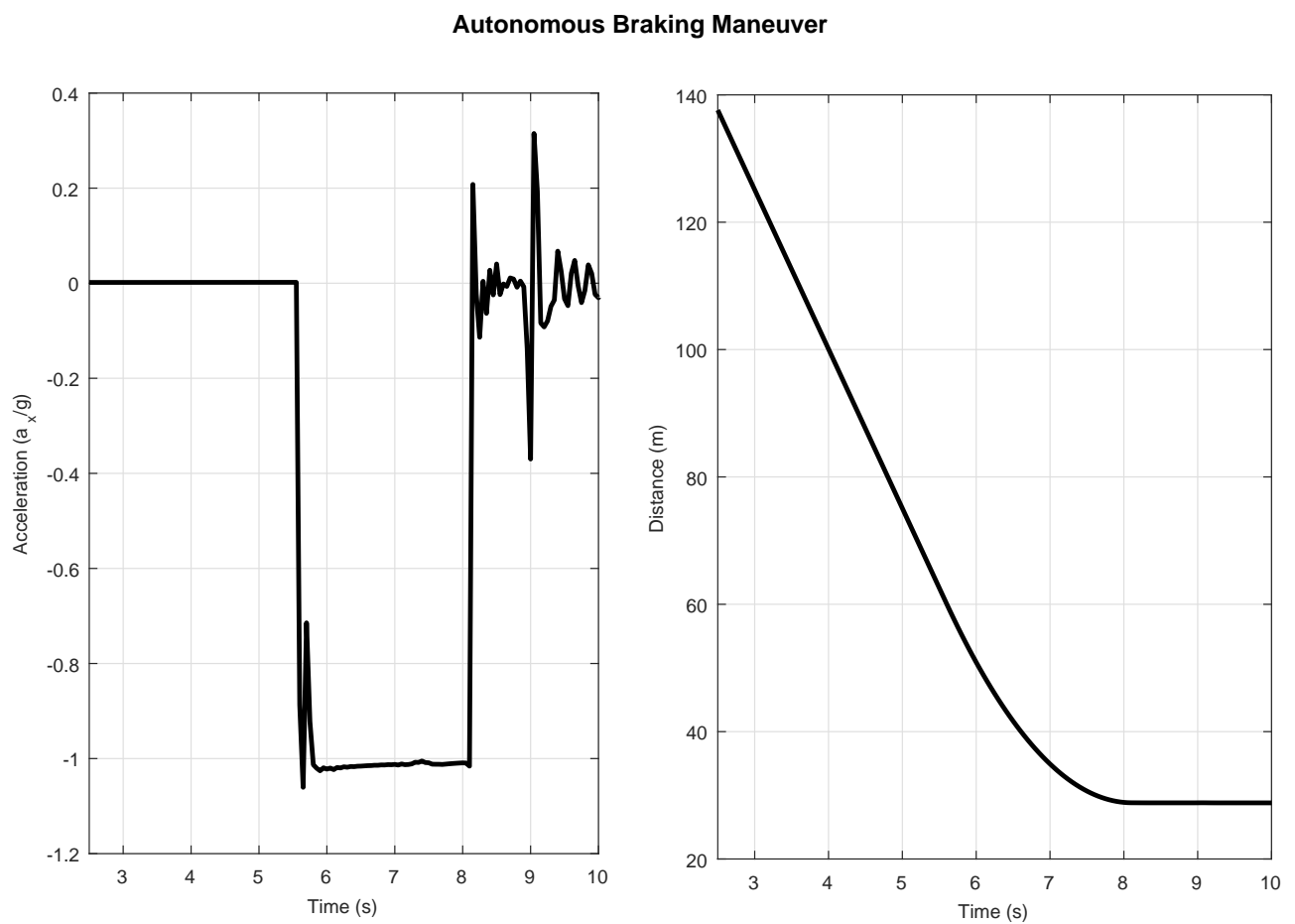

Figure 5.10: Autonomous braking maneuver.

As expected, the longitudinal acceleration output was similar to the Figure 5.5. The main purpose of this simulation was to check if the time-tocollision concept would be a suitable approach to use in an emergency situation. This particular result shown that in normal friction conditions, the time-tocollision provides a good information about the risk of an accident and can be used to trigger the collision avoidance system. Another simulations were done in different vehicles using a range of initial speeds and friction coefficients and it was observed that for normal or slightly low friction, the autonomous braking controller is able to stop the car. For critical friction conditions, the 
risk of collision is higher, not because of a low performance of the system, but due to the lack of friction to provide enough deceleration and stop the car in a reasonable distance. For these situations, a proper avoidance maneuver would be steering, which will be the topic of study in next section.

\section{5}

\section{Steering Control}

In this section, the autonomous steering controller will be presented. The rule base was built in order to minimize the behavior differences between vehicles with understeering and oversteering driving tendencies. For this reason, the orientation information was used not only to guarantee that the vehicle will reach the set point with a proper orientation, but also to avoid large yaw amplitudes during the avoidance maneuver. The statements used for building the rule base generated a non-linear fuzzy surface control, shown in Figure 5.11 .

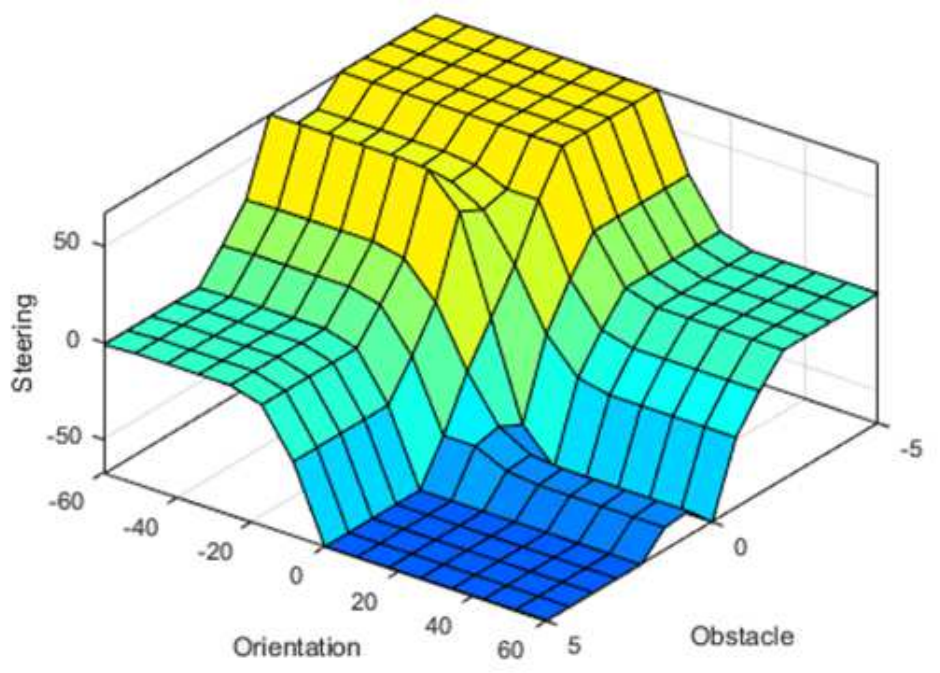

Figure 5.11: Fuzzy control surface for the steering control system.

The rule base contains some trivial statements to define a proper avoidance maneuver. The two first rules are activated when the obstacle is in front of the vehicle. The lateral relative position will be calculated comparing the geometric centers of the vehicle and the obstacle. If the obstacle is slightly to the right, then the vehicle will move to the left. As soon as the vehicle is approaching a safe region, the relative position variable will become "LOW RIGHT", which will result in a smaller steering wheel angle. The next rules are activated when the vehicle is about to reach a safe position. When the relative lateral position is "SAFE", the controller will care about aligning the vehicle in order to get it back to a straight line trajectory. Two special rules 
were included in order to compensate a possible oversteering behavior. When the yaw displacement is "HIGH LEFT" or "HIGH RIGHT", the controller will counter steer in order to avoid instabilities. Table 5.3 shows the complete rule base for controlling the vehicle through the steering maneuver. The lateral deviation between the vehicle and the obstacle and the vehicle's yaw angle were taken as input variables.

Table 5.3: Fuzzy control rules for the Steering control system.

\begin{tabular}{|c|c|c|}
\hline Relative lateral position & Orientation & Steering input \\
\hline Right & -- & Left \\
\hline Left & -- & Right \\
\hline Low Left & - & Low Right \\
\hline Low Right & -- & Low Left \\
\hline Safe & Right & Low Left \\
\hline Safe & Left & Low Right \\
\hline-- & High Left & Right \\
\hline-- & High Right & Left \\
\hline Safe & Zero & Zero \\
\hline
\end{tabular}

The approach of considering the lateral deviation between both vehicles was taken because of simulations purposes. This variable was used to have an offset lateral distance as a setpoint for the controller. This idea is perfectly feasible considering the available technology, but a simpler lane change approach can be used with this same controller and its concept will be presented later on this work.

\section{6}

\section{Autonomous Avoidance Maneuver}

The simulations for the avoidance maneuver were done considering mid-size and full-size vehicles, with understeering and oversteering driving tendencies. These simulations had the objective to analyze the trajectory and the steering wheel inputs for a vehicle with both driving tendencies. The midsize vehicle position and orientation during the avoidance maneuver are shown in Figure 5.12.

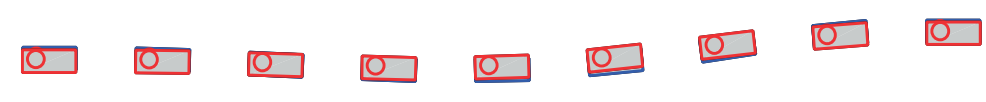

Figure 5.12: Steering inputs for oversteering and understeering vehicles.

The red and blue rectangles represents the understeering and oversteering vehicles respectively. The difference between both trajectories was unnoticeable, what makes possible to conclude that the controller was able to perform 
the emergency steering maneuver and also handle vehicles with different driving tendencies. Despite both vehicles had followed a similar path, the steering inputs given by the controller were different for each one. It is also important to remember that the steering maneuver must impose a reasonable acceleration at the vehicle. As discussed in Chapter 3, if a normal passenger car is considered, the acceleration values must not exceed $\frac{\dot{v}}{g}=1.0\left(9.8 \mathrm{~m} / \mathrm{s}^{2}\right)$. The lateral acceleration and steering wheel input values for both maneuvers are shown in Figure 5.13.
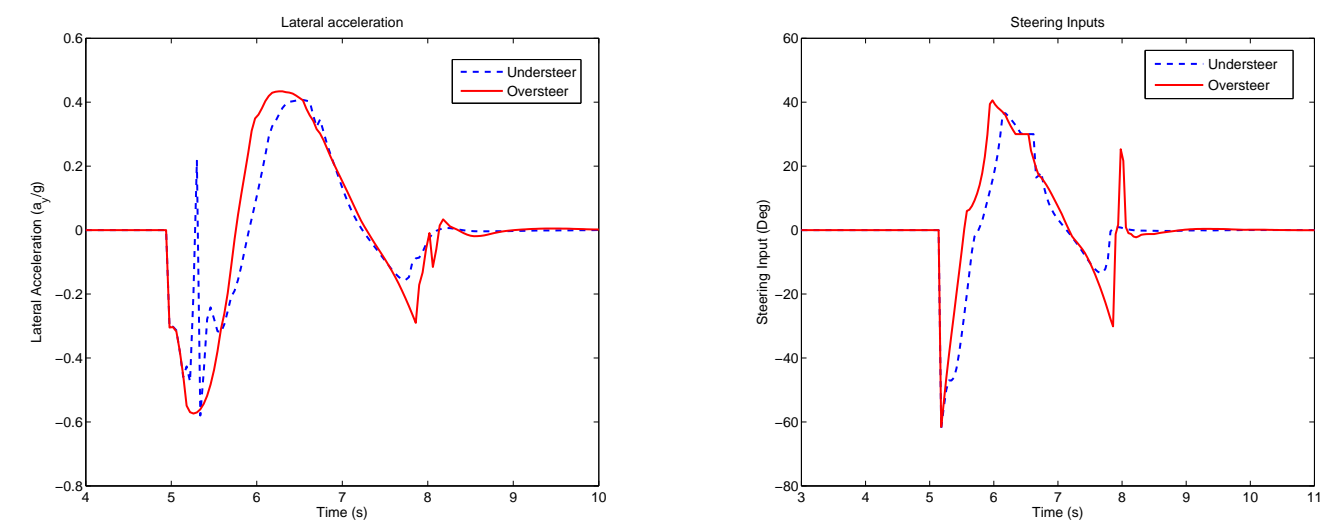

Figure 5.13: Lateral acceleration and steering inputs.

The resulting acceleration levels for this vehicle were acceptable considering the available friction limits for a normal track. The absolute acceleration values were always above $\frac{\dot{v}}{g}=0.6$, this value can be considered the main factor for having a unnoticeable trajectory difference between the understeering and oversteering vehicles. Another benchmark for analyzing the controller's performance was done by reducing the friction coefficient of the track to $\mu=0.3$, in order to simulate a low friction condition.

Analyzing the position and orientation of the vehicle, a higher difference between understeering and oversteering vehicles was noticed. Moreover, both vehicles performed oscillations before entering in a steady state condition (Figure 5.14). Nevertheless, considering the critical friction situation, the controller's performance can be considered satisfactory (Figure 5.15).

The avoidance maneuver was also simulated at the Apollo N, with similar results compared to the passenger cars. No modification was done at the steering controller's rule base for simulating it in the Apollo N, even with the mentioned special tires and the different steering system ratio when compared with a normal passenger car. The lateral acceleration output is shown in Figure 5.16. 

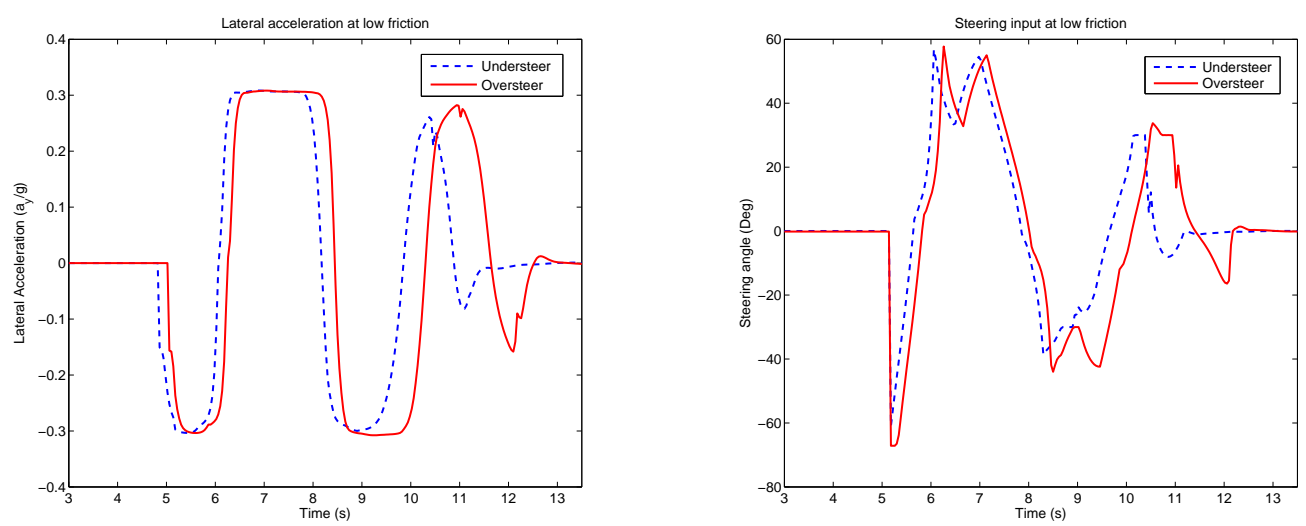

Figure 5.14: Lateral acceleration and steering inputs for $\mu=0.3$.

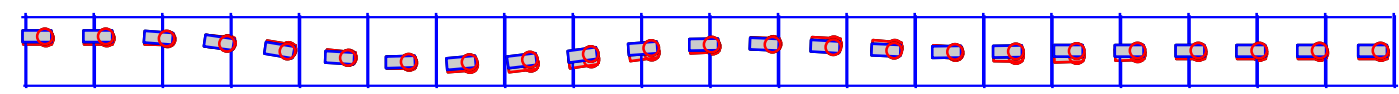

Figure 5.15: Avoidance maneuver in a low friction surface $(\mu=0.3)$.

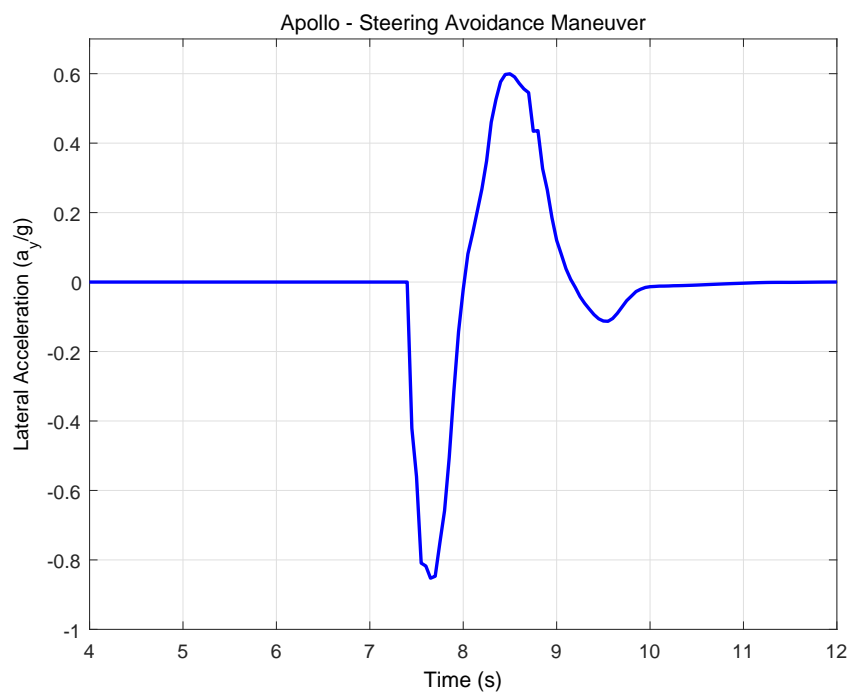

Figure 5.16: Avoidance maneuver performed at the Apollo N.

As expected, the acceleration peak was higher compared with the passenger cars. This result can be explained by the tire characteristics mentioned before and for the different steering ratio, once that for the same steering wheel angle, the Apollo $\mathrm{N}$ will have more wheel angular displacement than a normal passenger car.

\section{7}

\section{Combined Maneuver}

The results in Section 5.6 points that the system operates in a reasonable lateral acceleration range. Once the tires are able to generate even more forces, 
the possibility of having a combined maneuver must be taken into account. In this section these technical and safety trade-offs will be analyzed in order to find an appropriate approach for it.

In combined avoidance maneuvers, a normal driver would try to avoid the obstacle and stop the vehicle at the same time. The system is able to reproduce this behavior, but this approach is considered very dangerous. If this procedure is executed in a highway, for example, a stopped vehicle can collide with another cars coming from the back or from the other line.

In race vehicles an understeering tendency is highly undesirable. When it happens, the normal reaction of a racing driver is to hit the brake pedal while making the turn. As mentioned in Chapter 2, this action will cause a dynamic reaction, increasing the loads at the front wheels and decreasing at the rear, what will result in a momentary oversteering behavior. Figure 5.17 shows the vehicle's center of mass position at the $x y$-plane for a simulation done by combining a steering wheel step input and a braking torque.

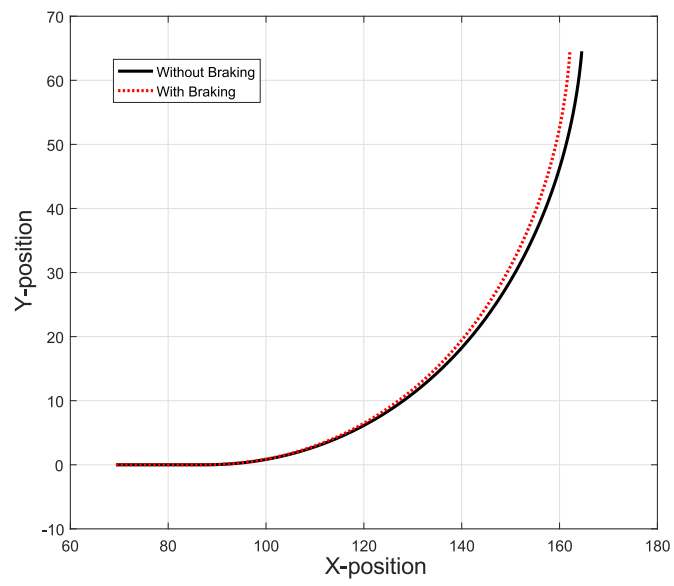

Figure 5.17: Comparison of a combined steering and braking maneuver with pure steering.

The simulation shown in Figure 5.17 was done with a steering angle of $90^{\circ}$. When a brake impact is applied, the vehicle follows a path with a slightly smaller radius. This procedure can produce better results in race or super sportive cars, because of the mentioned steering system ratio. After analyzing Figure 5.17, this maneuver was considered inadequate because of two main reasons:

- The procedure applies only for race vehicles. Special characteristics makes these vehicles able to perform turns in lower radius, the earnings can be considered relevant in a lap of $4 \mathrm{~km}$ in a race track, but not in shorter emergency maneuvers. 
- For producing this result, the steering wheel amplitude considerably higher than the controller outputs in the simulations done in Section 5.6 .

If the vehicle is above $100 \mathrm{~km} / \mathrm{h}$ and the road has normal friction, there is a great chance to avoid a collision by only applying the brakes. This maneuver is safer than steering, since the vehicle has no risk of colliding with another one driving at the other lane. Considering these possibilities, another approach was studied. When the system detects an imminent collision, the brakes will be immediately triggered and the longitudinal acceleration measured. If an insufficient braking distance is detected, then the brakes are released and the steering control system is activated. This approach makes the system safer and able handle particular situations when the friction coefficient suddenly changes.

A simulation scenario was built in order to evaluate the maneuver change. The friction coefficient was set to $\mu=0.3$, what forced the system to activate the steering control. Figure 5.18 presents values of vehicle's longitudinal and lateral accelerations, together with a graphical illustration of the simulation. The maneuver change can be identified when the longitudinal deceleration drops and the steering maneuver generates the lateral acceleration.
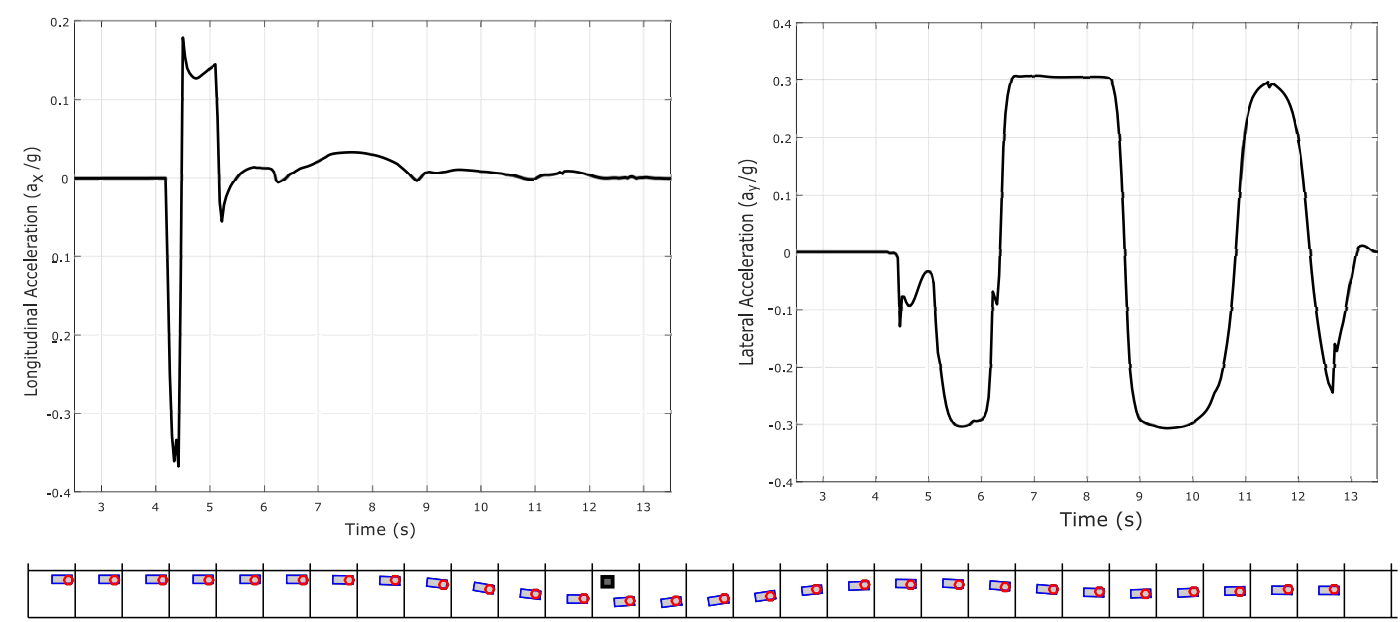

Figure 5.18: Changing between braking and steering maneuvers.

Considering that a steering maneuver requires a smaller space to be done and it is a good alternative for low friction conditions, the approach of switching between the braking and steering maneuvers was considered the more appropriated. Considering that the steering maneuver is needed in low friction conditions, braking and steering at the same time would reduce even more the vehicle's cornering capabilities in a critical situation, when naturally the tire is not able to generate a considerable amount of force. 


\section{6 \\ Implementation and Experiments}

After making simulations with all the data sets, the system was implemented in a scaled vehicle (Figure 6.1) in order to validate the mathematical model and proof the collision avoidance concepts developed in the theory. Despite being a 1:5 scaled model, the vehicle has some similar characteristics when compared with a normal passenger car, as for example, a similar friction coefficient with the road and a hydraulic brake system at the front wheels.

The use of such a vehicle reduces drastically the experiment costs and the risk of accidents during the tests. Besides the low costs for building, a scaled vehicle does not demand a special track and support for being tested, which combined with the portability of the whole system, made possible to execute a great number of tests during this research.

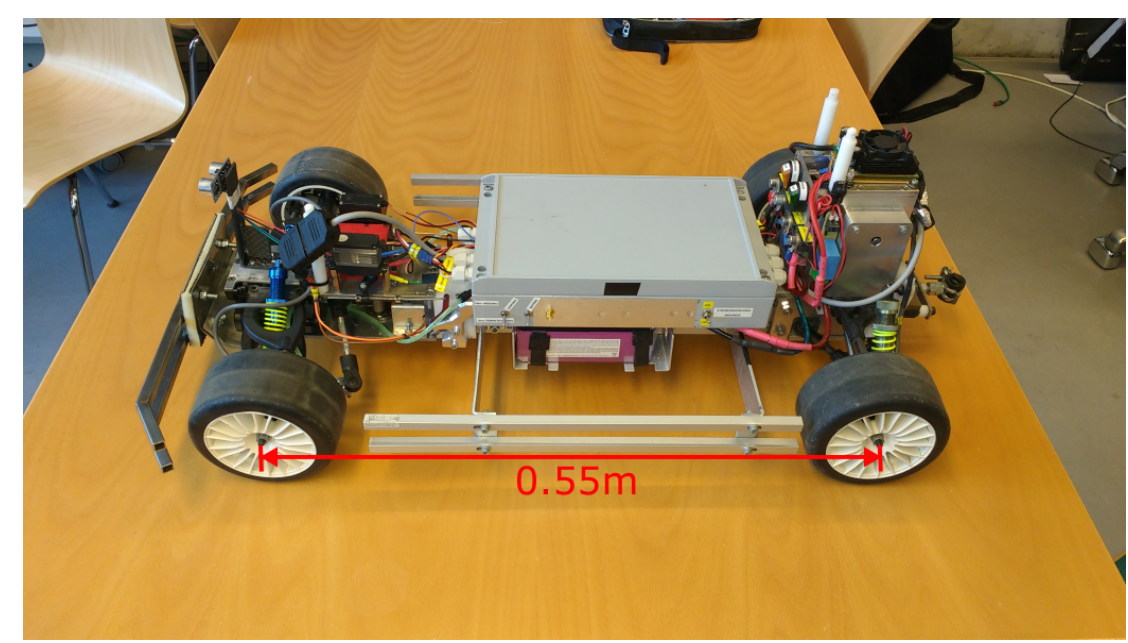

Figure 6.1: Scaled Vehicle.

The same low cost politics was adopted when specifying the electronics. No special hardware was used for implementing this system and all the sensors and boards are available in normal hobby stores. The vehicle's electronics systems will be better described in next sections. 


\section{1}

\section{Acquisition System}

The vehicle is equipped with a real time data acquisition system, which is able to save a log file in a SD card and transmit if through a network socket via $\mathrm{Wi}-\mathrm{Fi}$ at the same time. A Raspberry Pi was chosen as the main controller of the system, responsible to gather information about all the sensors and transmit it via network. An inertial measurement unit (IMU) was connected with the Raspberry Pi trough an $I_{2} C$ Bus. This unit is composed by two chips: a MPU6050 and a HMC58831, which made possible to measure accelerations and angular speeds in all directions and absolute angular displacements in the Z-axis.

An Arduino board is responsible for gathering information from another set of sensors and send it to the Raspberry Pi trough an USB connection. It is equipped with hall sensors to measure the wheel speeds and an analog steering wheel angle sensor. The distance between the vehicle and the obstacle is measured with an ultrasonic sensor. Figure 6.2 shows an overview of the vehicle's electronics circuits.

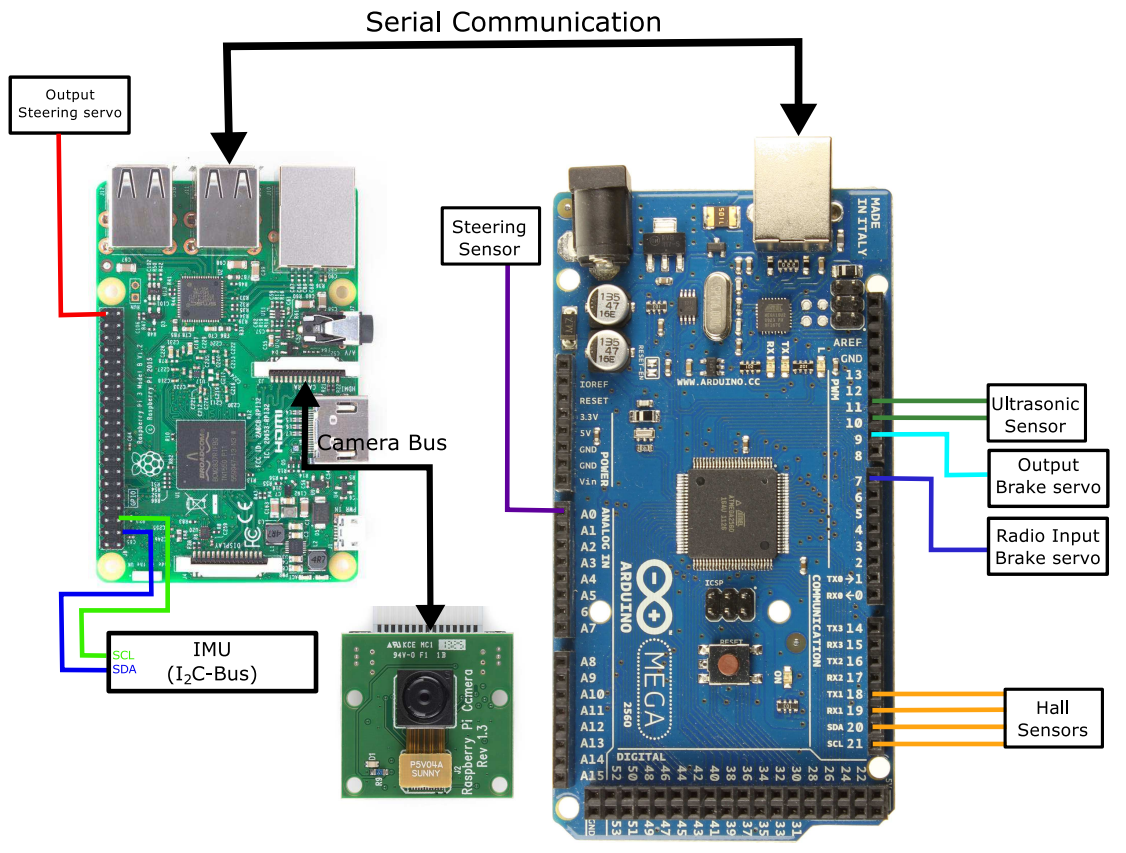

Figure 6.2: Simplified circuit schematic. 
The wheel speeds were measured by fixing magnets at the rims. Each wheel has a set of 8 magnets and a hall sensor, which will send pulses to the Arduino board and generate code interrupts in order to estimate the wheel angular speeds. As the same way of the simulations, the vehicle speed is estimated by taking the mean value of the four wheel speeds. This information will be used together with the distance measurement to estimate the time-tocollision.

A graphical user interface (GUI) was built using LabVIEW, which was used for making a network connection between the Raspberry Pi and a regular $\mathrm{PC}$ and show all the signals in real time. The interface has small real time graphs of the main signals, which can be sent to the main window by using a selection button, as illustrated in Figure 6.3.

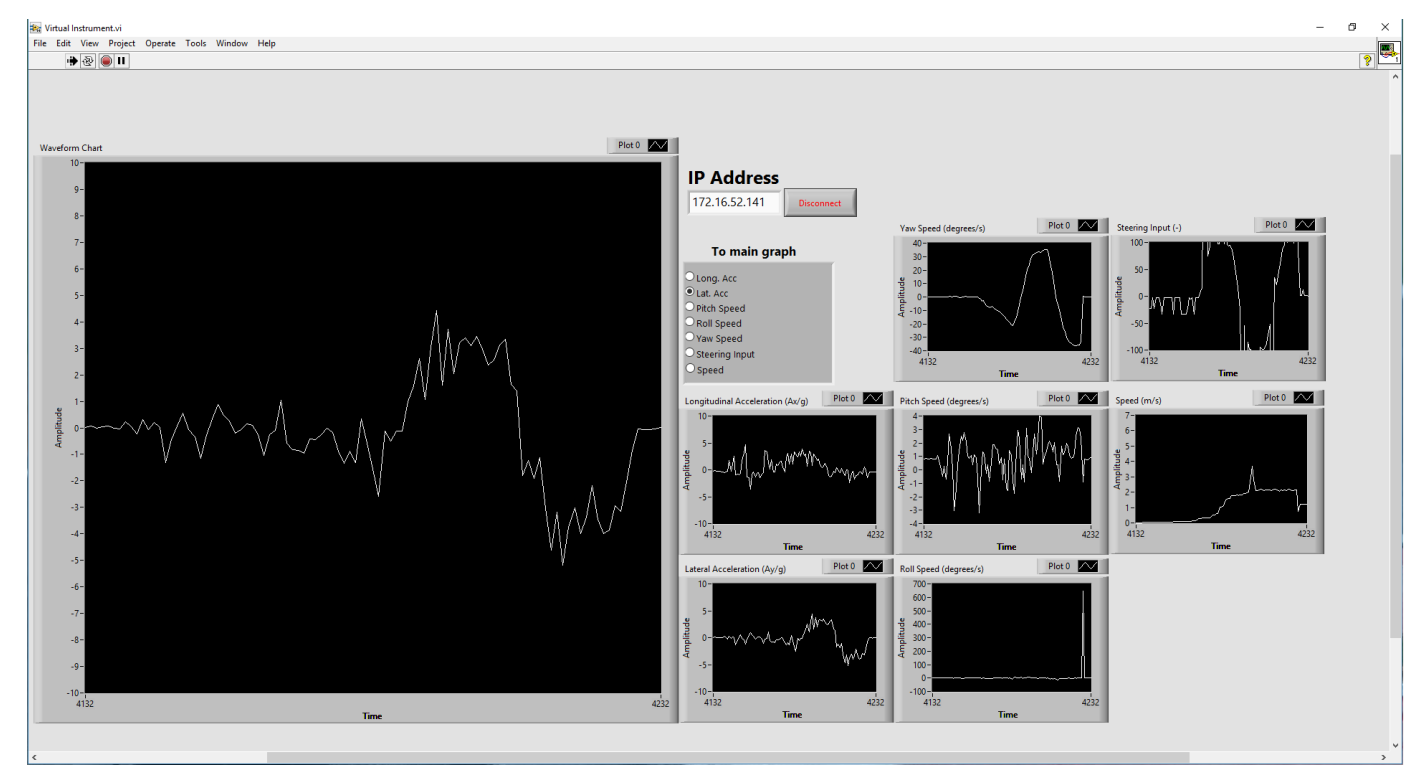

Figure 6.3: Data Acquisition GUI.

\section{2}

\section{Model Validation}

Before starting the experiments, a new data set for MATLAB was built using information from a previous model of the scaled vehicle done in ADAMS. This procedure was executed to validate the mathematical model by making a standard maneuver and comparing acquired data with the model outputs. The double lane change was chosen to be a proper maneuver for making the model validation, once it is a highly dynamic maneuver used as handling assessment for real vehicles. The comparison between the real maneuver and the simulation can be seen in Figure 6.4.

The maneuver was first executed using the scaled model in a low friction $\operatorname{road}(\mu \approx 0.4)$ and constant speed $(v \approx 5 \mathrm{~m} / \mathrm{s})$. After the experiment, the 

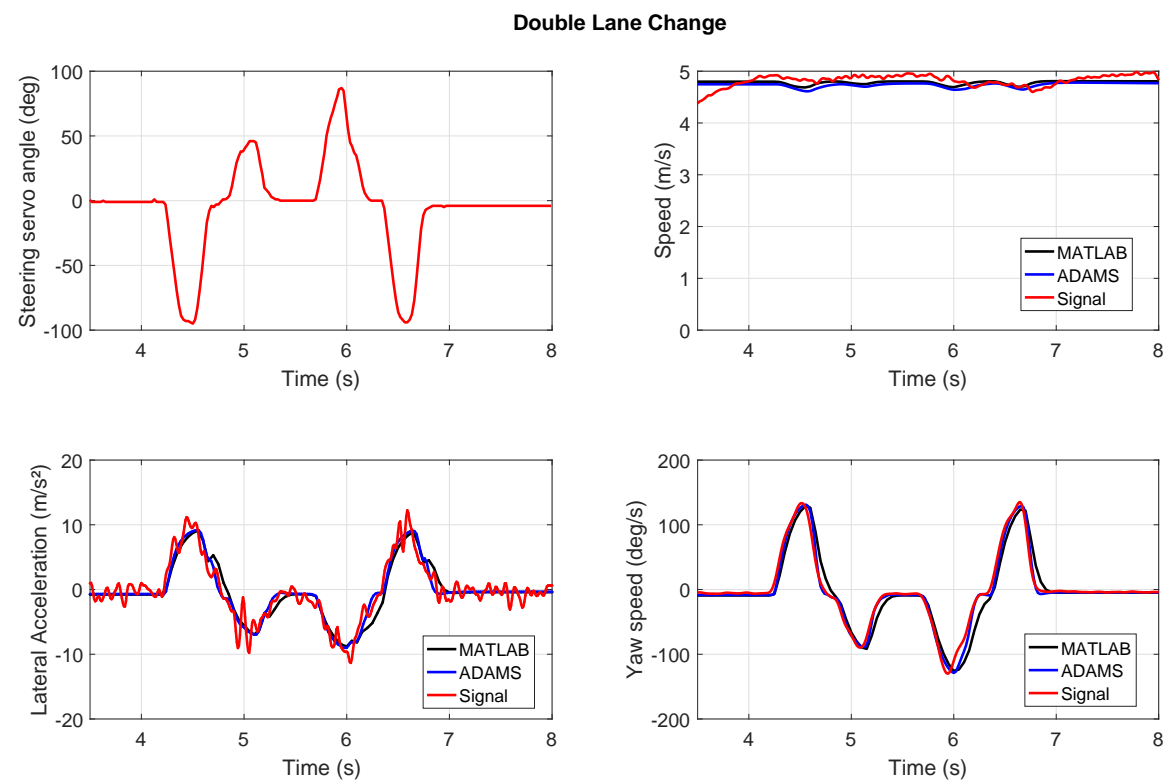

Figure 6.4: Double Lane Change maneuver comparison.

acquired data from the steering wheel angle was used as an input for the simulation in MATLAB. Measurements of lateral acceleration and yaw speed were used to validate de maneuver and as Figure 6.4 shows, the simulation outputs were similar to the acquired signals. Considering that it was not possible to acquire data from a significant amount of road vehicles, this validation was taken as an indicator that the MATLAB model is able to reproduce the behavior of a real car with a reasonable accuracy.

\section{3}

\section{ABS Controller}

The ABS Fuzzy controller was implemented in $\mathrm{C}++$ using the eFLL (18) library and the Arduino board, once it is directly connected to the speed sensors. The fuzzy sets were defined using the passenger car approach as reference and the brake torque output was remapped into a servo angle, once it is the actuator responsible to drive the hydraulic mechanism to brake the wheels.

\subsection{1}

\section{Braking in Straight Line}

The initial step to analyze the ABS performance is to execute straight line braking maneuvers. In the first experiment, the vehicle was braked on a surface with normal friction without the ABS control. It is important to highlight that the wheel speeds are calculated by the time difference of two 
pulses generated by the magnets. For this reason, a wheel lock will not be read as zero speed, it will be noticed when there is a considerable amount of longitudinal acceleration, but the wheel speed remains constant. The acquired data from front wheels' speed and longitudinal acceleration is shown in Figure 6.5 .

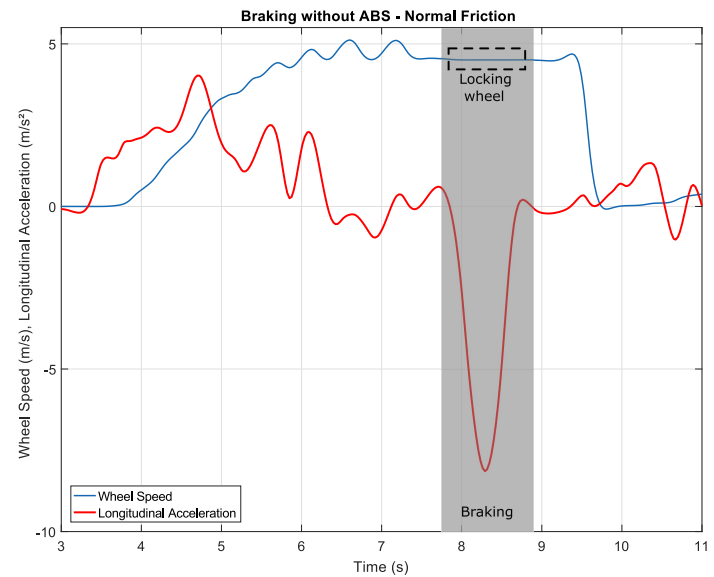

Figure 6.5: Scaled Vehicle braking without ABS.

As expected, when the full power was applied at the brakes, the front wheels locked instantly. Despite having a considerable amount of longitudinal acceleration, the tires entered in the saturation region and are not able to generate lateral forces when it is required. The same experiment was repeated with the ABS controller turned on. The signals of wheel speed and longitudinal acceleration are shown in Figure 6.6.

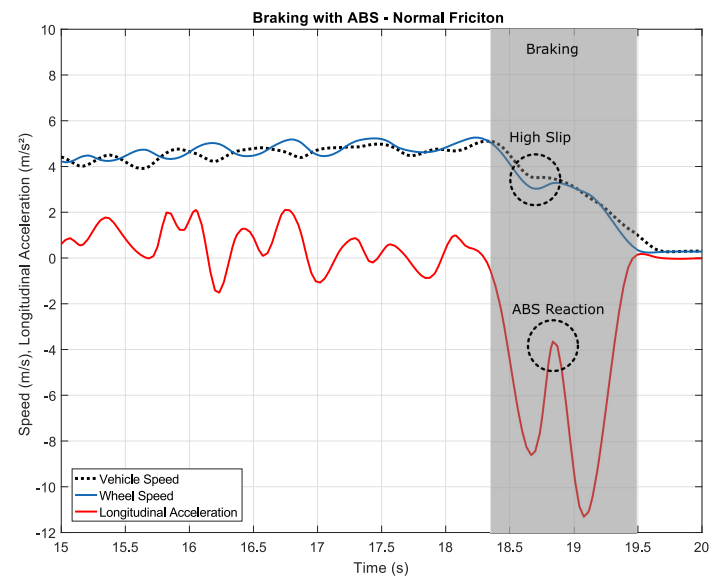

Figure 6.6: Scaled Vehicle braking with ABS. 
In the second experiment, the influence of the ABS controller can be noticed when the vehicle velocity is compared with the wheel speed. The dashed circle in Figure 6.6 shows a considerable difference between both speeds, which will make the ABS controller release the braking force in order to reduce the slip. This action can be noticed when the longitudinal acceleration drops and the wheel speed get closer to the vehicle velocity. Another point to highlight is that during the braking maneuver, the vehicle probably drove over a lower friction region, which explains why the longitudinal acceleration dropped to such a low value for a longer time than expected. This hypothesis can be justified by the two peaks of longitudinal acceleration. The first peak happens around $8 \mathrm{~m} / \mathrm{s}^{2}$, which is enough to increase the slip to a considerable level. What does not happen in the second peak, when the value reaches $11 \mathrm{~m} / \mathrm{s}^{2}$ and the wheel speed is kept close to the vehicle velocity. This situation is also common in real world, once the surfaces have a non-uniform friction distribution.

The last experiment to evaluate the controller's performance was a straight line braking in a surface with low friction conditions $(\mu \approx 0.35)$. In this condition, the ABS controller is very susceptible to operate in the unstable range described in Section 5.3. Figure 6.7 shows the signals of speeds and longitudinal acceleration for the third experiment.

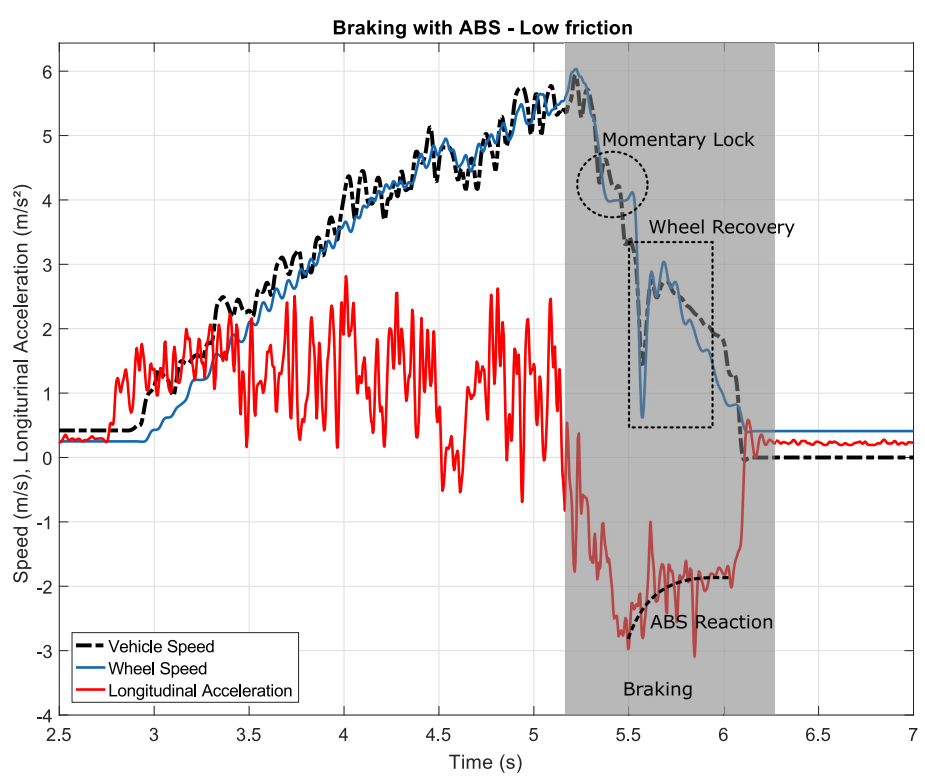

Figure 6.7: ABS test in low friction. 
Even in commercial systems, it is common to have momentary wheels locks when braking in low friction surfaces, what also happened in the experiment (dashed circle). The ABS reaction is highlighted for a dashed line, which shows how the braking power was reduced in order to make the wheel spin again.

\subsection{2}

\section{Braking and Steering}

The last evaluation of the ABS controller was to observe how the system would manage to control the brake force during a steering maneuver. The longitudinal and lateral accelerations, together with the steering input data were acquired in order to make a comparison of the same vehicle performing the braking and steering maneuver on the same surface. In the first experiment, the maneuver was executed without the ABS controller. In Figure 6.8, the dashed rectangles shows the time interval where the maneuver was executed and the gray region highlights when the wheels were locked.

Braking and Steering Without ABS
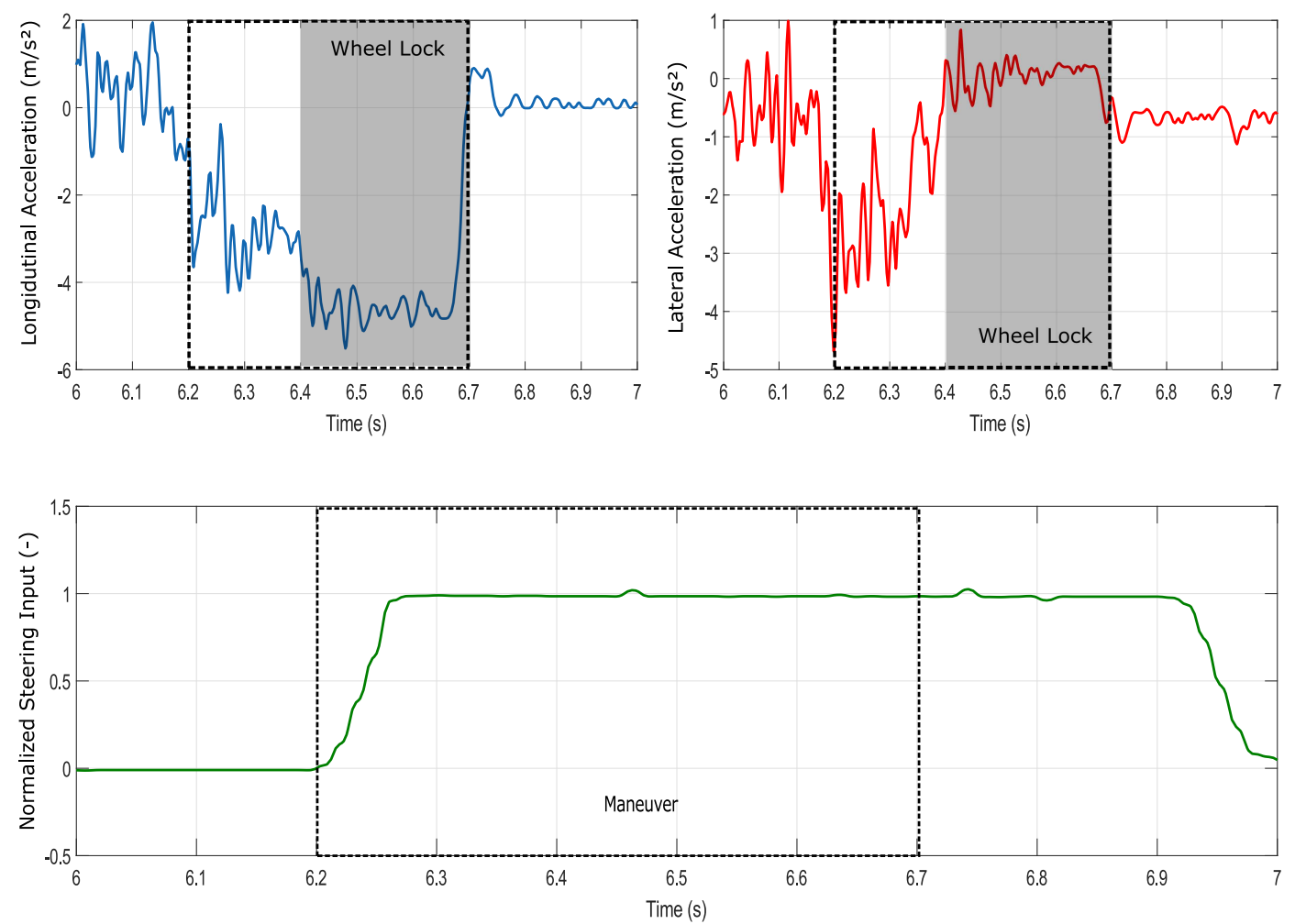

Figure 6.8: Braking and Steering maneuver using the scaled model.

The typical behavior for a car with locked front wheels was observed. In the maneuver's beginning, there was a combination between longitudinal and lateral force generation, but as soon as the wheels are locked, the tires enter in the saturation region and no lateral forces were generated. This is a clear 
indicator of the interdependence between the longitudinal and lateral forces, discussed in Section 4.1. The same experiment was repeated with the ABS controller turned on and despite the wheels were locked and released twice during the maneuver, it was clear that the ABS controller improved the handling performance. This improvement is noticeable by analyzing the lateral acceleration signal, which shows that the vehicle was able to generate lateral forces during most of the maneuver and when the wheels entered in the saturation region, the ABS controller released the brake power immediately. Figure 6.9 shows the acceleration and steering signals for the second experiment.

Braking and Steering With ABS
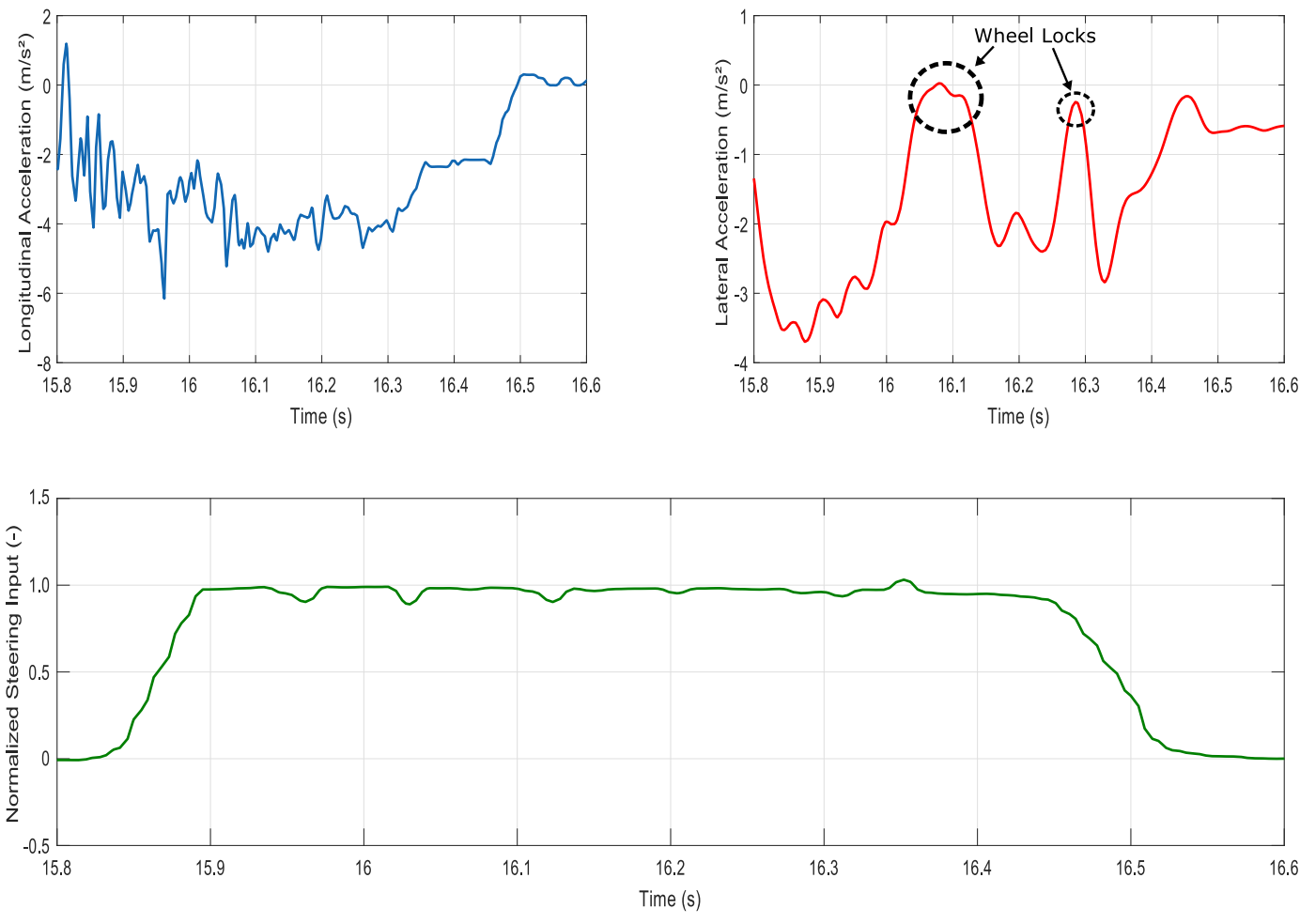

Figure 6.9: Braking and Steering maneuver using the scaled model and ABS controller.

After thee different experiments, the ABS controller's overall performance was considered reasonable, once it was able to manage braking in surfaces with different and non-uniform friction conditions and to keep the vehicle's stability during a steering maneuver. The next and final step of the autonomous braking system development is to trigger the ABS controller by using the time-to-collision concept and observe if the vehicle is able to avoid colliding with an obstacle. This experiment is the topic of study in next section. 


\subsection{3}

\section{Autonomous Braking Test}

The autonomous braking maneuver is the final assessment for this system. Previous experiments were made following the same concept of triggering the system when $T T C \leq 1.5$, but due to the maximum speed of the scaled model $\left(V_{\max } \approx 6 \mathrm{~m} / \mathrm{s}\right)$ and the high power of the braking system, the vehicle was stopping far away to collide with the obstacle. In this experiment, the software was modified to trigger the brakes with $T T C \leq 0.75$. This modification was also made because the ultrasonic sensor is able to measure distances up to $4.5 \mathrm{~m}$, which combined to the top speed of the vehicle, will result in TTC $=0.75$. In order to make the experiment even more interesting, in case of $T T C \geq 0.75$, the brakes will be released and the control will be given back to the driver. Figure 6.10 shows the signals acquired in the autonomous braking experiment.
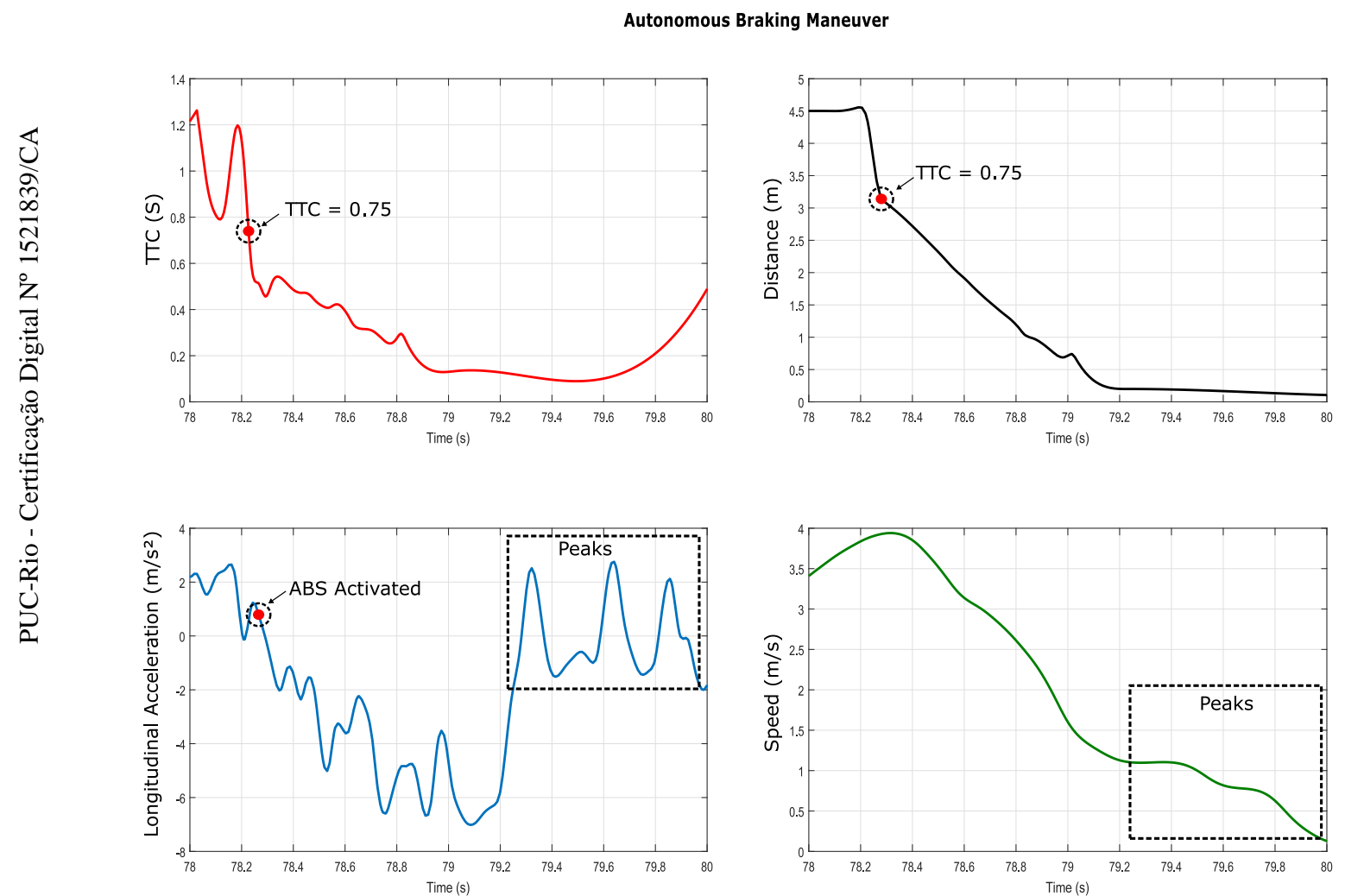

Figure 6.10: Autonomous Braking Maneuver using the scaled model.

The ABS controller operates in high frequency and induces noises in the wheel speed signals. For this reason, theses signals were filtered in order to provide a better visualization of the hole maneuver. The TCC signal is a function of the speed, and it was also affected by this noise. Considering that, the TTC signal was also filtered before being plotted. This noise becomes higher at low wheel speeds once the ABS operating frequency is even higher. 
The combination of all these factors was responsible for generating acceleration peaks during the end of the experiment, once the throttle was kept in $100 \%$ during all the time. These peaks can be seen at the dashed rectangles in Figure 6.10. Despite this behavior, the controller was able to stop the vehicle before colliding with the obstacle. Considering also that the critical TTC value was reduced by the half and the vehicle reached deccelerations up to $7 \mathrm{~m} / \mathrm{s}^{2}$ during the maneuver, the system's final evaluation was very positive.

\section{4}

\section{Vision System Concept}

In this section, a simple strategy will be presented in order to show how to generate a position feedback to the autonomous steering controller. This solution was chosen considering the main idea of this work, which is demonstrate simple and effective solutions using low cost hardware. The vision system concept will be based on a simple road lane recognition algorithm, which was considered the best solution to run in real time at the Raspberry Pi.

The algorithm was developed using $\mathrm{C}++$ and $\mathrm{OpenCV}(14,15)$. This library has a great range of functions implemented to work with image processing and segmentation. The main advantages of using the OpenCV are the huge documentation and examples available at the official website and the fact of being a open source and multi-platform library, which could be used in the Raspberry Pi without any special modification compared to a normal PC.

\subsection{1}

\section{Algorithm Development}

The OpenCV allows to have a wide range of approaches to solve the problem of identifying objects. The funcitons are able to segment images by simple color and shape detections, but more complex features as Machine Learning and Feature recognition are also possible. These complex features are able to not only detect an object but also to classify it as a car, tree or any interesting object previously defined. The main problem of these approaches is the computation power needed to execute it, which makes unreasonable to have a machine learning algorithm with object classification running in real time on a Raspberry Pi.

In the OpenCV environment, every image is composed by three $N-b y-M$ matrices, where $N$ and $M$ are the image's size in pixels. These three matrices are called channels, responsible to store the color information, which can be for example, the amount of red, green and blue of the respective pixel. In this 
algorithm, the first step will be to convert the colored image in a grayscale frame. The main advantage of making this procedure is that grayscale images are represented for a single $N-b y-M$ matrix, which stores values between 0 and 255 acording the amount of black and white of each pixel. This procedure will speedup every image operation, once they will be applied in one matrix instead of three. Figure 6.11 shows the image transformation to grayscale.

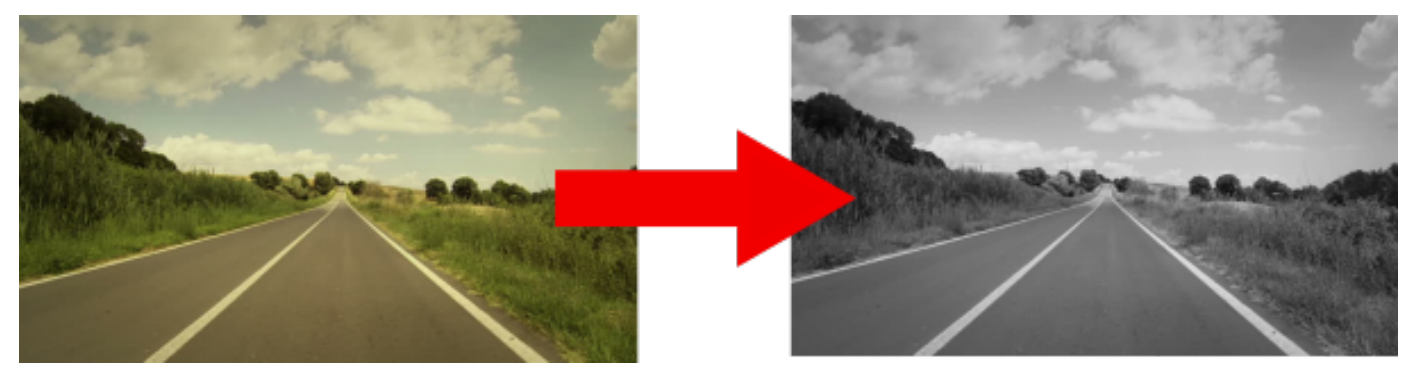

Figure 6.11: Image convertion from RGB to grayscale.

The approach to detect the lines is based on the fact of the asphalt always being darker than the lines painted at the road, which are normally yellow or white. Assuming that white pixels will be stored at the image matrix as 255 and black pixels will be stored as zero, a threshold operation was performed in the grayscale matrix in order to make zero (black) every pixel with a value smaller than a reference. This operation will transform all the darker pixels in black, making easier for the software to distinguish between the lines and the asphalt. An illustration of this procedure is shown in Figure 6.12.

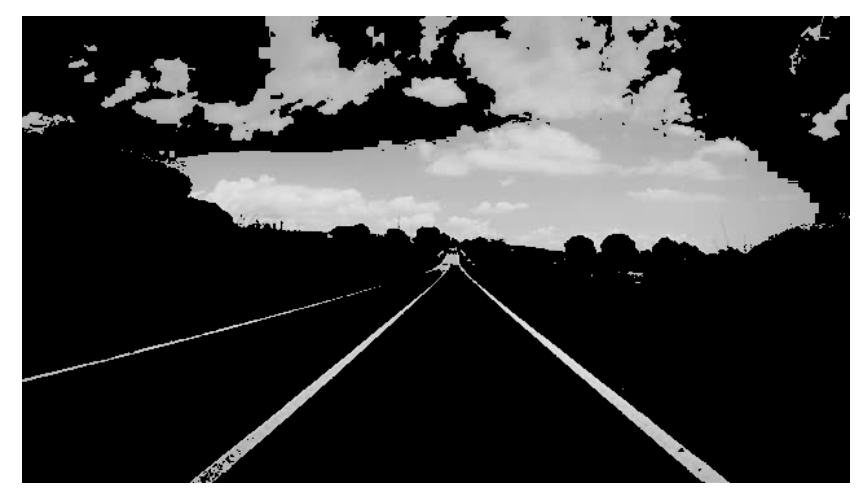

Figure 6.12: Grayscale after threshold operation.

After thresholding the image, the dark regions at the asphalt and the surroundings were eliminated, but the clouds and the sky are still present at the image, once this elements also have a considerable amount of white. The method to solve this problem is based on the region on interest (ROI) concept. Assuming that in a passenger car, the pitch and roll angles will be small, the image will always have the same ratio between asphalt and sky in the frame. 
Considering this information, a small region of interest was defined at the lower part of the image and all the higher pixels were set to black by performing a element-wise multiplication between the frame and a defined mask, as shown in Figure 6.13.
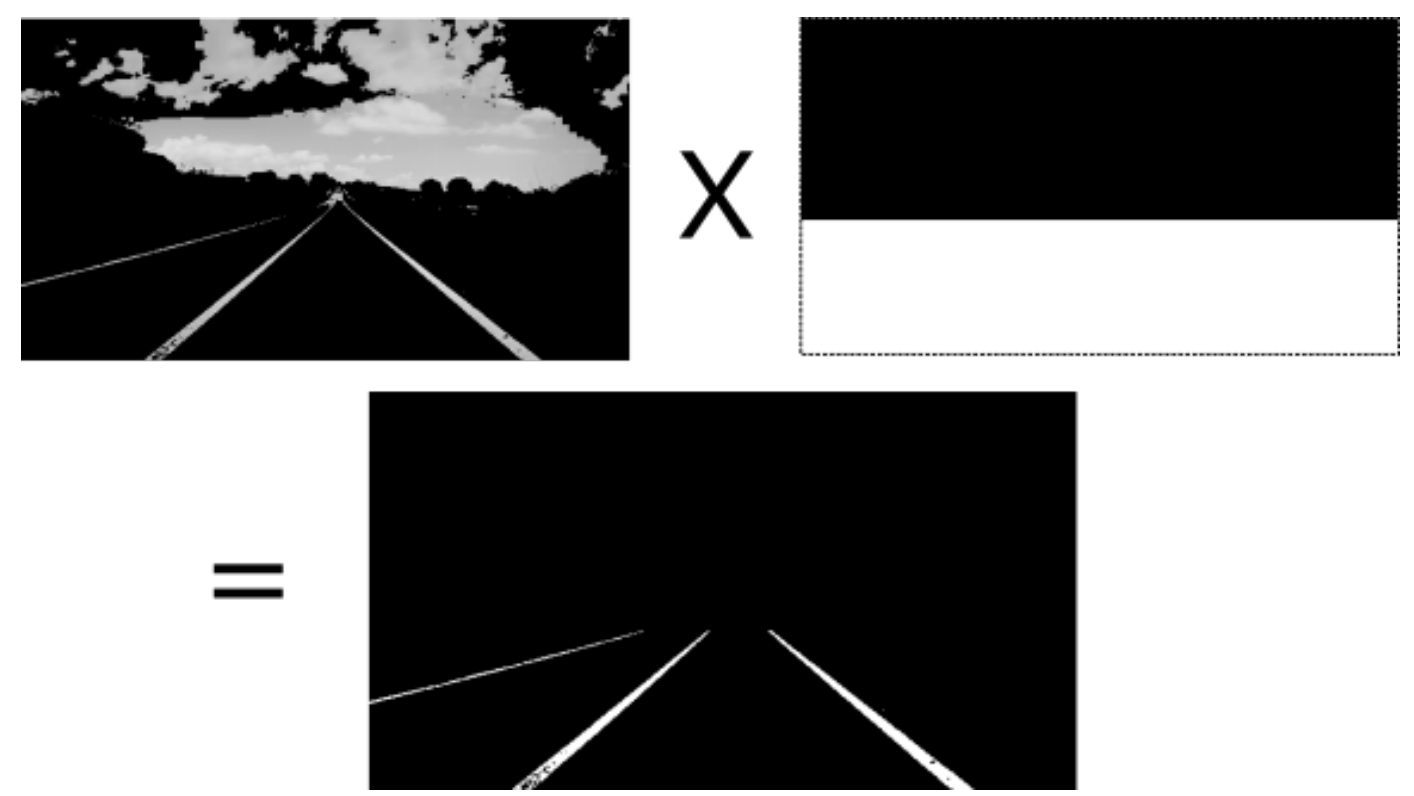

Figure 6.13: Mask introduction at the thresholded image.

Despite being effective to remove the clouds and the sky, the main advantage of setting up a region of interest is the possibility to process only a specific area from the image, this means that in a matrix operation, a smaller part of the frame will be processed which results in a calculation speedup.

After the thresholding and masking operations, the image is ready to be processed and the first step is to look for the remaining contours on it. The function findContours() is implemented at the OpenCV library and will be the responsible for analyzing the image and storing a vector of points. This information defines a set of contours related to the road's white lines. With these points, the function approxPolyDP() will be used. This function receives a vector of contours points and tries to estimate a polygon for each contour and store the vertices' information in another vector of points. Considering that every line has four vertices, the estimation was build by creating two mean points at the polygon's upper and the lower parts, as demonstrated in Figure 6.14 .

After this procedure, the road lines could be estimated in a reasonable and fast way. Each loop iteration was performed in approximately 50ms, which is a acceptable time considering that the autonomous steering controller will work in a considerably lower frequency range than the ABS controller. Figure 6.15 shows an overview of the system working on the Raspberry Pi 


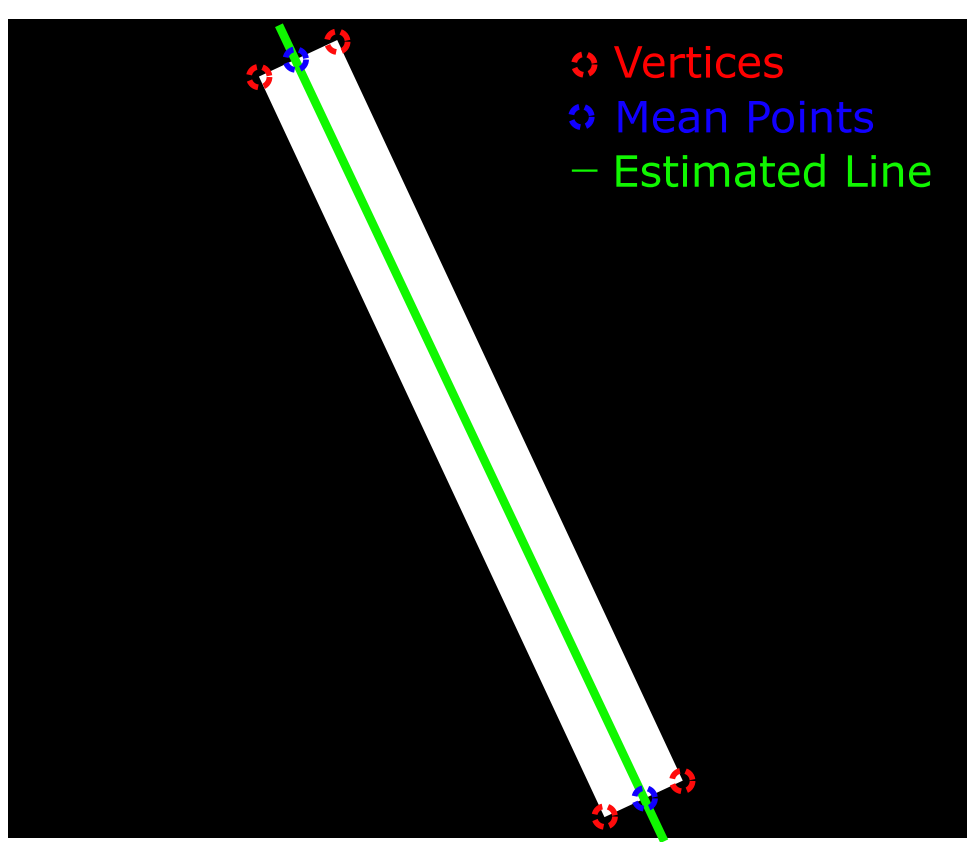

Figure 6.14: Line estimation algorithm.

environment. In this Figure, the polygons are drawn in blue and one of the estimated lines can be seen in the right side of the track. The loop time is also printed at the terminal window, at the left.

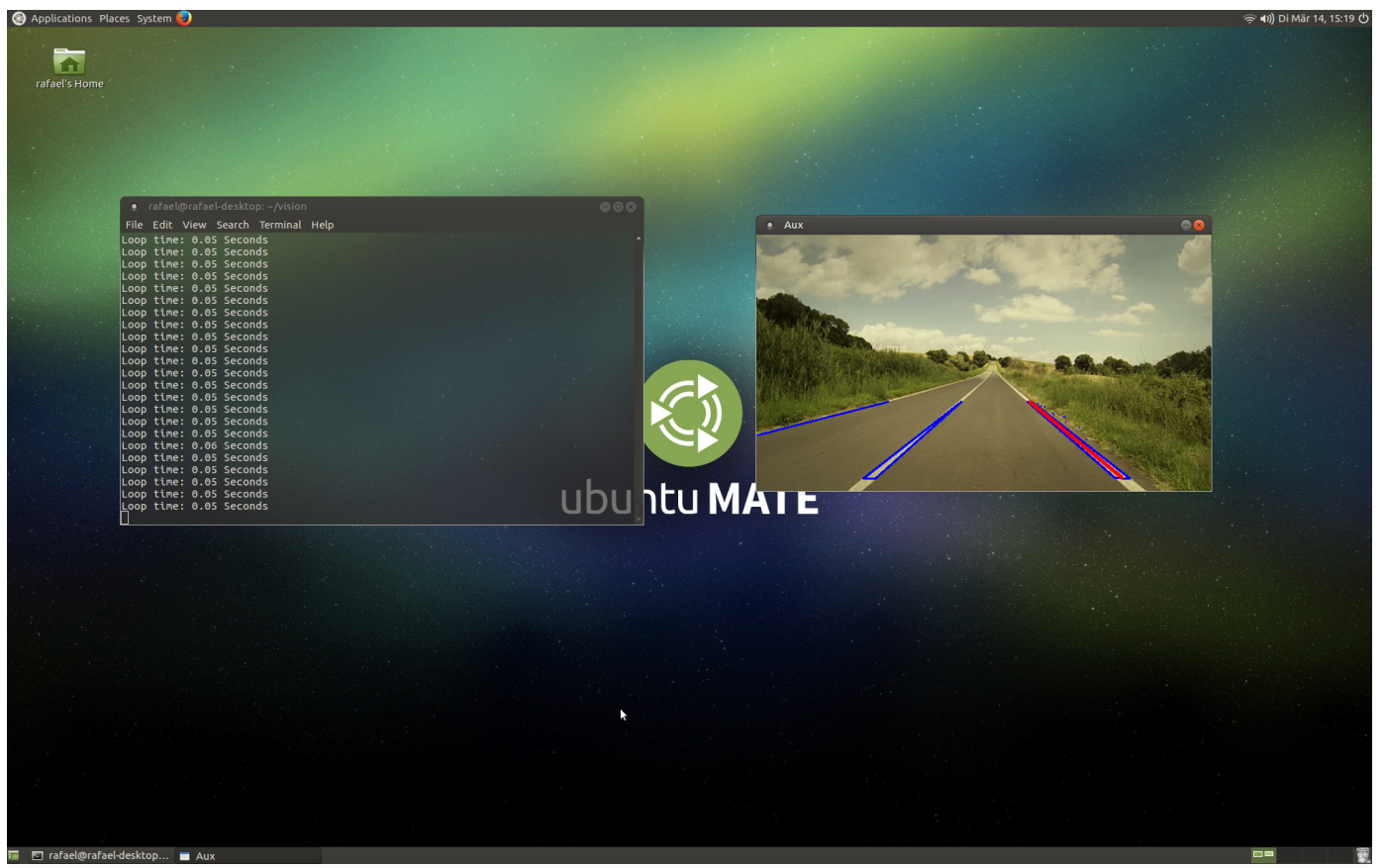

Figure 6.15: Final output of the vision system. 


\section{5 \\ Recommendations for the Autonomous Steering Control}

A simple way to implement the autonomous steering control is to use it together with the lane detection algorithm. Assuming that the lines were detected, the system may create a separate region of interest for each road lane and find any kind of object present on it. As soon as the autonomous braking controller notices an impossible braking distance, the vision system must look for available lanes in order to perform a single lane change maneuver to the left or right side.

This approach may work in highways, but it should have a worse performance in cities. Due to the high number of elements in the frame, detecting the road lines will be a harder task. This weakness can be overcome, once that if a high traffic scenario is considered, the vehicle will probably be in a reduced speed and the autonomous braking system will be able to handle the situation without triggering the steering controller. On other hand, the use of more complex algorithms and a more powerful hardware can improve the video detection system. For example, if the mentioned machine learning approach is used for identifying pedestrians, it can reduce considerably the number of city accidents. This can be done by replacing ultrasonic sensor by a stereo vision system, which can be capable to detect objects in the surroundings and estimate the distances between the vehicle and each one of those. 


\section{Conclusions}

Despite not having an optimum performance at a super sportive car braking in low friction conditions, the ABS controller presented good results in normal friction when simulated with the Apollo N. It has also shown a good performance when simulated with the passenger cars braking on roads with different friction coefficients. Another good results were obtained in simulations with $\mu$-split conditions, where the vehicle must brake in a surface with different friction coefficients at the left and right wheels without spinning.

The steering controller also had a satisfactory performance. The system was tested in understeering and oversteering passenger vehicles and also in a super sportive car. The avoidance maneuver was performed successfully and no modification was necessary to adapt the passenger car controller at the Apollo N, what is considered a relevant aspect when evaluating the overall performance of the system.

In normal friction conditions, most of the times a braking maneuver is enough for avoiding a collision. The passenger cars were capable to execute safe braking maneuvers for lower values of road friction when compared with the Apollo $\mathrm{N}$ and the reasons for it were explained in Chapter 5. Considering the critical braking distance at low friction conditions and the good performance of the autonomous steering system, a combined maneuver was studied. After analyzing three different scenarios, it was considered that the most appropriate maneuver would be switching between braking and steering, depending on the available distance to brake.

Taking the studies and simulations into account, a collision avoidance algorithm was build in order to tell the controller when it is appropriated to trigger each autonomous system. The time-to-collision was chosen as a risk measurement variable and used to trigger the autonomous braking system. After that, the longitudinal acceleration is measured for a period of time and the system estimates if it is possible to stop the vehicle for a given distance until the obstacle. In case of an insufficient braking distance, the steering system is triggered, which made possible for the controller to perform avoidance maneuvers in a wide range of day-by-day situations.

The experiments done with the scaled model provided good results 
regarding the ABS controller performance. Tests were made using slick and groove tires in different friction conditions and the controller was able to handle most of them. An electrical motor is installed at the rear wheels, which induces a natural braking force every time the throttle is released. Because of this fact, it was impossible to test the vehicle in even more critical friction conditions, once the rear wheels would lock and the speed feedback would be not valid anymore.

Regarding the autonomous steering system, the controller tested in simulations may be used together with the vision system in order to have a position feedback. Highly sophisticated algorithms can be implemented in order to detect and classify objects, but the simple approach of detecting available road lanes is considered a reasonable, simple and computationally cheap approach. This system can be implemented in the future and tested with this same model in a scaled track.

Video processing techniques are also interesting for a considerable range of applications in the automotive field. Once the wheels are always submitted to slip, it will be very interesting to measure the vehicle's speed in a precise way using a camera and any video processing feature such as Optical Flow. This would be an important progress in the field of vehicle safety since the vehicle's speed, the wheel slips and the side-slip angle would be also measured and not only estimated as it is currently done. 


\section{References}

[1] CAStRo, A. A.; ChaVES, R. B.; RILL, G. ; WEBER, H. I.. Use of integrated control to enhance the safety of vehicles in run-offroad scenarios. In: DINAME, São Sebastião, SP, Brazil, 2017.

[2] CHAVAN, A.; YOGAMANI, S. K.. Real-time dsp implementation of pedestrian detection algorithm using hog features. In: ITS TELECOMMUNICATIONS (ITST), 2012 12TH INTERNATIONAL CONFERENCE ON, p. 352-355. IEEE, 2012.

[3] CHAVES, R. B.; RILL, G. ; WEBER, H. I.. Fuzzy braking and steering control approach for a collision avoidance system. In: APPLIED RESEARCH CONFERENCE, p. 435 - 440, Augsburg, Germany, 2016.

[4] CHEN, S.-L.; CHENG, C.-Y.; HU, J.-S.; JIANG, J.-F.; CHANG, T.-K. ; WEI, H.-Y.. Strategy and evaluation of vehicle collision avoidance control via hardware-in-the-loop platform. Applied Sciences, p. 327, 2016.

[5] CHEN, L.; BIAN, M.; LUO, Y.; QIN, Z. ; LI, K.. Tire-road friction coefficient estimation based on the resonance frequency of inwheel motor drive system. Vehicle System Dynamics, 54(1):1-19, 2016.

[6] CHEN, L.; LUO, Y.; BIAN, M.; QIN, Z.; LUO, J. ; LI, K.. Estimation of tire-road friction coefficient based on frequency domain data fusion. Mechanical Systems and Signal Processing, 85:177-192, 2017.

[7] CHOI, S. B.. Antilock brake system with a continuous wheel slip control to maximize the braking performance and the ride quality. IEEE Transactions on Control Systems Technology, 16(5):9961003, 2008.

[8] DOI, A.; BUTSUEN, T.; NIIBE, T.; TAKAGI, T.; YAMAMOTO, Y. ; SENI, $H$.. Development of a rear-end collision avoidance system with automatic brake control. JSAE Review, 15(4):335-340, 1994.

[9] EICKE, S.; BUSCH, A.; WIELITZKA, M.; ZEMKE, S.; TRABELSI, A.; DAGEN, M. ; ORTMAIER, T.. Tire road friction estimation for improvements to traction control during drive off maneuvers in vehicles. 
In: CONTROL APPLICATIONS (CCA), 2016 IEEE CONFERENCE ON, p. 917-922. IEEE, 2016.

[10] European New Car Assessment Programme (Euro NCAP). http://www . euroncap.com/. Accessed: 03/2017.

[11] FARGIONE, G.; TRINGALI, D. ; RISITANO, G.. A fuzzy-genetic control system in the abs for the control of semi-active vehicle suspensions. Mechatronics, 39:89-102, 2016.

[12] GREEN, M.. "how long does it take to stop?" methodological analysis of driver perception-brake times. Transportation human factors, 2(3):195-216, 2000.

[13] HIRSCHBERG, W.; RILL, G. ; WEINFURTER, H.. Tire model tmeasy. Vehicle System Dynamics, 45(S1):101-119, 2007.

[14] ITSEEZ. Open source computer vision library. https://github. com/itseez/opencv, 2015.

[15] ITSEEZ. The opencv reference manual. http://opencv.org/, 2014.

[16] JAZAR, R. N.. Vehicle dynamics: theory and application. Springer Science \& Business Media, 2013.

[17] KAHARMEN, H. M.; KUSTONO, D.; KAMDI, W.; TUWOSO; PUSPITASARI, P.; PUSPITASARI, P.; SURYANTO, H.; PERMANASARI, A. A.; PUTRA, A. B. N. R.; INDRA, F. ; OTHERS. Design of integrated wheel slip-skid factor and vehicle side slip angle using mamdani fuzzy control. In: AIP CONFERENCE PROCEEDINGS, volumen 1778, p. 030030. AIP Publishing, 2016.

[18] KRIDI, D. S.; DE OLIVEIRA ALVES, A. J.; DE SOUSA LEMOS, M. V. ; OTHERS. Desenvolvimento de uma biblioteca fuzzy para o controle autônomo de um robô móvel em ambiente desconhecido. Mostra Nacional de Robótica, 1, 2013.

[19] LENARD, J.; BADEA-ROMERO, A. ; DANTON, R.. Typical pedestrian accident scenarios for the development of autonomous emergency braking test protocols. Accident Analysis \& Prevention, 73:73-80, 2014.

[20] LIU, M.; CHIEN, S. ; CHEN, Y.. Improve road safety using combined v2v and pre-collision systems. In: THE 24TH INTERNATIONAL 
TECHNICAL CONFERENCE ON THE ENHANCED SAFETY OF VEHICLES (ESV2015), p. 8-11, 2015.

[21] MATSCHINSKY, W.. Radführungen der Straßenfahrzeuge: Kinematik, Elasto-Kinematik und Konstruktion. Springer-Verlag, 2007.

[22] MATSUI, Y.; HAN, Y. ; MIZUNO, K.. Performance of collision damage mitigation braking systems and their effects on human injury in the event of car-to-pedestrian accidents. Stapp car crash journal, 55:461, 2011.

[23] MILANÉS, V.; PÉREZ, J.; GODOY, J. ; ONIEVA, E.. A fuzzy aid rear-end collision warning/avoidance system. Expert Systems with Applications, 39(10):9097-9107, 2012.

[24] MILANÉS, V.; LLORCA, D. F.; VILLAGRÁ, J.; PÉREZ, J.; FERNÁNDEZ, C.; PARRA, I.; GONZÁLEZ, C. ; SOTELO, M. A.. Intelligent automatic overtaking system using vision for vehicle detection. Expert Systems with Applications, 39(3):3362-3373, 2012.

[25] National Highway Traffic Safety Administration and others: Motor vehicle traffic crash fatality counts and estimates of people injured for 2005. DOT HS, 810:639, 2006.

[26] NIETO, M.; LABORDA, J. A. ; SALGADO, L.. Road environment modeling using robust perspective analysis and recursive bayesian segmentation. Machine Vision and Applications, 22(6):927-945, 2011.

[27] NVIDIA automotive, driving innovation. http://www. nvidia. com/object/drive-automotive-technology.html. Accessed: 03/2017.

[28] RAJAMANI, R.; PHANOMCHOENG, G.; PIYABONGKARN, D. ; LEW, J. Y.. Algorithms for real-time estimation of individual wheel tireroad friction coefficients. IEEE/ASME Transactions on Mechatronics, 17(6):1183-1195, 2012.

[29] RIEKERT, P.; SCHUNCK, T.-E.. Zur fahrmechanik des gummibereiften kraftfahrzeugs. Ingenieur-Archiv, 11(3):210-224, 1940.

[30] RILL, G.. Road vehicle dynamics: fundamentals and modeling. CRC Press, 2011.

[31] RILL, G.; SCHAEFFER, T.. Grundlagen und Methodik der Mehrkörpersimulation. Springer, 2010. 
[32] RILL, G.. Tmeasy: A handling tire model based on a threedimensional slip approach. In: PROCEEDINGS OF THE XXIII INTERNATIONAL SYMPOSIUM ON DYNAMIC OF VEHICLES ON ROADS AND ON TRACKS (IAVSD 2013). Quingdao, China, 2013.

[33] Roborace official website. http://roborace.com/. Accessed: 03/2017.

[34] SANTA, J.; TOLEDO-MOREO, R.; ZAMORA-IZQUIERDO, M. A.; ÚBEDA, B. ; GÓMEZ-SKARMETA, A. F.. An analysis of communication and navigation issues in collision avoidance support systems. Transportation research part C: emerging technologies, 18(3):351-366, 2010.

[35] TANG, B.; CHIEN, S.; HUANG, Z. ; CHEN, Y.. Pedestrian protection using the integration of $\mathrm{v} 2 \mathrm{v}$ and the pedestrian automatic emergency braking system. In: INTELLIGENT TRANSPORTATION SYSTEMS (ITSC), 2016 IEEE 19TH INTERNATIONAL CONFERENCE ON, p. 2213-2218. IEEE, 2016.

[36] WOITSCH, G.; SINZ, W.. Influences of pre-crash braking induced dummy-forward displacements on dummy behaviour during euroncap frontal crashtest. Accident Analysis \& Prevention, 62:268275, 2014.

[37] World Health Organization - Global status report on road safety 2013., 2015.

[38] ZADEH, L. A.. Probability measures of fuzzy events. Journal of mathematical analysis and applications, 23(2):421-427, 1968. 